\title{
Conceptual Design for Lower-Energy Primary Aluminum
}

\begin{abstract}
N.A. WARNER
Operating parameters have been identified such that slag melts typical of other carbothermic aluminum processes are thermodynamically unstable. This facilitates the direct reaction of carbon in carbon-saturated aluminum with alumina under dispersed-contact high-intensity conditions. A conceptual design for one million tonnes per annum (1 Mtpa) aluminum production from Bayer alumina is developed. Freestanding graphite reactors and an ancillary plant encapsulated by inert gas are totally unconstrained within refractory-lined shells. Electrical conductive heating and melt circulation in closed loops, employing a $10 \mathrm{vol}$ pct dispersion of fine carbon particles in aluminum (slurry), transports sensible heat to a single pressurized metalproducing reactor (MPR) to satisfy the endothermicity. In the proposed plant, an MPR at $0.28 \mathrm{MPa}(2.8$ bar $)$ and $2433 \mathrm{~K}\left(2160{ }^{\circ} \mathrm{C}\right)$ with a hearth 2 -m-wide $\times 190$-m-long leads the melt via a barometric leg back to essentially atmospheric pressure, for further in-line processing. The impeller-stirred assimilation of fine carbon particles is followed by multistage gas-lift pumping to provide a 5.4-m total head, as required by two parallel straight-line melt-conductive heaters $1 \mathrm{~m}$ in diameter $\times 226 \mathrm{~m}$ in length. Overall energy-consumption figures 28.7 pct lower than today's more recently installed Hall-Heroult electrolytic plants are predicted, with 51.3 pct less purchased electricity, supplemented with 1.10 times the stoichiometric elemental carbon.
\end{abstract}

DOI: $10.1007 / \mathrm{s} 11663-008-9134-\mathrm{x}$

(C) The Minerals, Metals \& Materials Society and ASM International 2008

\section{INTRODUCTION}

ACCORDING to Bruno in 2003, ${ }^{[1]}$ “....production of aluminum by carbothermic reduction has been investigated by every major aluminum company over the past 47 years. As an alternative to the Hall-Heroult process, carbothermic offers potential energy cost and environmental advantages, if solutions to critical technical problems identified by previous research, could be developed." The key issues are listed as follows:

(a) efficient delivery of energy to attain $2000{ }^{\circ} \mathrm{C}$ to $2200{ }^{\circ} \mathrm{C}$;

(b) recovery of mass and energy values associated with volatile aluminum-containing species;

(c) effective decarbonization of the Al-C metal phase; and

(d) recovery of energy values in the byproduct $\mathrm{CO}$, to reduce net energy consumption.

The challenges identified by Bruno listed here are accepted and potentially viable solutions proposed and rigorously evaluated. However, there is total rejection of the conclusion drawn by Welch, ${ }^{[2]}$ who claims that "...carbothermic processing on an energy analysis is extremely poor." On the other hand, a new approach is definitely called for and, in this regard, the strongly held view is that what is needed is an evaluation of how conductive heating and melt circulation can be mustered

N.A. WARNER, Emeritus Professor, is with Department of Chemical Engineering, University of Birmingham, Birmingham,

United Kingdom. Contact e-mail: warnerna@btopenworld.com

Manuscript submitted January 14, 2008.

Article published online March 28, 2008. to provide the framework for overcoming the critical technical issues.

By operating above atmospheric pressure, the adverse energy implications associated with the concurrent evolution of aluminous vapors $\left(\mathrm{Al}_{2} \mathrm{O}_{(g)}, \mathrm{Al}_{(g)}\right)$ can be reduced to manageable proportions. This suggests that operating a pressurized reactor containing a homogeneous single-liquid phase of carbon-saturated aluminum fed with preheated alumina is a technically feasible option, whereas at atmospheric pressure, the losses would be totally unacceptable. Modern iron blast furnaces operate at top pressures as high as 3.2 atmospheres absolute (3.24 bar). ${ }^{[3]}$ On the other hand, avoidance of excessively high temperatures is thermodynamically favored by lower pressures. Accordingly, after assessment of a range of operating pressures, 2.8 bar was selected as a compromise between the evolution of volatile species and the upper temperature limitations.

Certain simple design precepts related to melt-circulation systems in general need to be enunciated, as compliance with these is absolutely essential for the new technology about to be explored.

(a) All parts of a melt-circulation loop or circuit need to be capable of being heated to the melting point, to facilitate startup and, indeed, restarting after a prolonged shutdown. If electrical conductive heating (i.e., direct-resistance heating) is envisaged in the process under steady-state operation, it is necessary to ensure that sufficient energy can be provided to all parts of the melt-circulation loop to stop the melt from freezing in the event of a temporary shutdown.

(b) For longer-term shutdown, the melt within the loop must be removed before freezeup, to prevent 
damage to the melt-containment structural components on remelting. The corollary to this is that the holdup of melt within an operating loop must be kept as small as possible, consistent with the essential process-engineering requirements.

Melt circulation is proposed as the key to lowerenergy aluminum production. It opens up the potential for truly continuous processing with minimal labor intensity and without the adverse environmental issues associated with the existing Hall-Heroult technology. There are neither fluoride emissions, anode baking emissions, nor problems associated with spent pot-lining disposal. All the endothermic requirements for producing aluminum are provided by conductive heating in external pipe melt-circulation loops carrying large alternating currents. The metal-producing reactor (MPR) and in-line ancillaries have independent electrical circuits designed to ensure adequate conductive heat input, to prevent freezeup in the event of departure from normal steady-state continuous operation.

The reaction zone within the MPR and associated downsteam in-line units operate at a maximum temperature of $2160{ }^{\circ} \mathrm{C}$. However, within the external pipe meltcirculation loops, the temperature reaches $2200{ }^{\circ} \mathrm{C}$. These figures need to be viewed in relation to the mechanical strength of industrial-grade synthetic graphites. Above a temperature of about $2400{ }^{\circ} \mathrm{C}$, there is a dramatic reduction in graphite strength, and excessive thermal creep sets in. Up to this temperature, the strength of graphite increases markedly above room-temperature values, as the temperature is progressively increased. Because of the anticipated, very extensive backmixing within the MPR reaction zone, the operating temperature effectively drops immediately to the exit temperature, which by design is set at $2160{ }^{\circ} \mathrm{C}$. Downstream from the circulating carbon-saturated $\mathrm{Al}$, the temperature continues to fall toward the region in which carbon saturation is replaced by $\mathrm{Al}_{4} \mathrm{C}_{3}$ saturation, a condition that must not be allowed to occur. The relevant part of the phase diagram, according to Qui et al., ${ }^{[4]}$ shows the lower temperature limit as $2160{ }^{\circ} \mathrm{C}$. A slightly lower temperature of $2156^{\circ} \mathrm{C}$ is given by Olden and McClune. ${ }^{[5]}$ It is essential to have the melt-circulation rate high enough to accommodate this critical requirement.

\section{PROCESS DESCRIPTION}

To overcome the inevitable attack of high-temperature alumina slag on graphite, conditions must be selected in which only a carbon-saturated metallic aluminum melt is thermodynamically stable. To achieve this objective, operation at a 2.8-bar total pressure $(0.28 \mathrm{MPa})$ requires a reactor temperature of at least $2160{ }^{\circ} \mathrm{C}(2433 \mathrm{~K})$. Table I reproduces the $\mathrm{HSC}^{[6]}$ evaluation of the chemical equilibria for this case. Figure 1 is the corresponding HSC4 equilibrium diagram showing that $\mathrm{Al}_{2} \mathrm{O}_{3}$ melts containing $\mathrm{Al}_{4} \mathrm{C}_{3}$ are not stable under the conditions selected. The input raw materials are $\mathrm{Al}_{2} \mathrm{O}_{3} 1.514 \mathrm{~mol}$, C $245 \mathrm{~mol}$ dissolved in aluminum, and free C $248 \mathrm{~mol}$ dispersed in carbonsaturated aluminum. These input data are those for a melt-circulation system containing carbon-saturated aluminum with about 10 vol pct dispersed carbon particles; these are typical of a circulating melt entering the

Table I. HSC4 Equilibrium Evaluation; Basis: 1 Mole $\mathrm{Al}_{2} \mathrm{O}_{3}$ Consumed or Production of 2 Moles Al (54 g); Input Temperature: $\mathrm{C}$ and $\mathrm{Al}=2433 \mathrm{~K}\left(2160^{\circ} \mathrm{C}\right), \mathrm{Al}_{2} \mathrm{O}_{3}=2223 \mathrm{~K}\left(1950{ }^{\circ} \mathrm{C}\right)$

\begin{tabular}{|c|c|c|c|c|c|}
\hline Temperature & $2433.15 \mathrm{~K}$ & & & & \\
\hline Pressure & 2.8 bar & & & & \\
\hline Volume & $3.372 \times 10^{-1} \mathrm{~m}^{3}(\mathrm{NTP})$ & & & & \\
\hline Reaction enthalpy & $2.047 \times 10^{3} \mathrm{~kJ}$ & & & & \\
\hline Reaction entropy & $8.786 \times 10^{2} \mathrm{~J} / \mathrm{K}$ & & & & \\
\hline Iteractions & $16($ limit $=100)$ & & & & \\
\hline Phase 1 & Input Amount (mol) & Equilibrium Amount (mol) & Mole Fraction & Activity Coefficient & Activity \\
\hline $\mathrm{O}_{2}(\mathrm{~g})$ & $0.0000 \times 10^{0}$ & $1.5467 \times 10^{-13}$ & $3.271 \times 10^{-14}$ & $1.00 \times 10^{0}$ & $3.271 \times 10^{-14}$ \\
\hline $\mathrm{O}(\mathrm{g})$ & $0.0000 \times 10^{0}$ & $5.1986 \times 10^{-9}$ & $1.099 \times 10^{-9}$ & $1.00 \times 10^{0}$ & $1.099 \times 10^{-9}$ \\
\hline $\mathrm{CO}(\mathrm{g})$ & $0.0000 \times 10^{0}$ & $4.1178 \times 10^{0}$ & $8.708 \times 10^{-1}$ & $1.00 \times 10^{0}$ & $8.708 \times 10^{-1}$ \\
\hline $\mathrm{CO}_{2}(\mathrm{~g})$ & $0.0000 \times 10^{0}$ & $4.8036 \times 10^{-5}$ & $1.016 \times 10^{-5}$ & $1.00 \times 10^{0}$ & $1.016 \times 10^{-5}$ \\
\hline $\mathrm{Al}_{2} \mathrm{O}(\mathrm{g})$ & $0.0000 \times 10^{0}$ & $4.2410 \times 10^{-1}$ & $8.969 \times 10^{-2}$ & $1.00 \times 10^{0}$ & $8.969 \times 10^{-2}$ \\
\hline $\mathrm{Al}(\mathrm{g})$ & $0.0000 \times 10^{0}$ & $1.8679 \times 10^{-1}$ & $3.950 \times 10^{-2}$ & $1.00 \times 10^{0}$ & $3.049 \times 10^{-2}$ \\
\hline $\mathrm{AlO}(\mathrm{g})$ & $0.0000 \times 10^{0}$ & $4.9594 \times 10^{-5}$ & $1.049 \times 10^{-5}$ & $1.00 \times 10^{0}$ & $1.049 \times 10^{-5}$ \\
\hline Total & $0.0000 \times 10^{0}$ & $4.7287 \times 10^{-0}$ & & & \\
\hline \multicolumn{6}{|l|}{ Phase 2} \\
\hline $\mathrm{Al}_{4} \mathrm{C}_{3}$ & $0.0000 \times 10^{0}$ & $0.0000 \times 10^{0}$ & $0.000 \times 10^{0}$ & $4.35 \times 10^{0}$ & $0.000 \times 10^{0}$ \\
\hline $\mathrm{Al}_{2} \mathrm{O}_{3}$ & $1.5140 \times 10^{0}$ & $0.0000 \times 10^{0}$ & $0.000 \times 10^{0}$ & $7.30 \times 10^{-1}$ & $0.000 \times 10^{0}$ \\
\hline Total & $1.5140 \times 10^{0}$ & $0.0000 \times 10^{0}$ & & & \\
\hline \multicolumn{6}{|l|}{ Phase 3} \\
\hline $\mathrm{C}$ & $2.4504 \times 10^{2}$ & $1.9652 \times 10^{2}$ & $1.704 \times 10^{-1}$ & $5.87 \times 10^{0}$ & $1.000 \times 10^{0}$ \\
\hline $\mathrm{Al}$ & $9.5507 \times 10^{2}$ & $9.5706 \times 10^{2}$ & $8.296 \times 10^{-1}$ & $8.99 \times 10^{-1}$ & $7.458 \times 10^{-1}$ \\
\hline Total & $1.2001 \times 10^{3}$ & $1.1536 \times 10^{3}$ & & & \\
\hline \multicolumn{6}{|l|}{ Phase 4} \\
\hline $\mathrm{C}$ & $2.4804 \times 10^{2}$ & $2.9245 \times 10^{2}$ & $1.000 \times 10^{0}$ & $1.00 \times 10^{0}$ & $1.00 \times 10^{0}$ \\
\hline Total & $2.4804 \times 10^{2}$ & $2.9245 \times 10^{2}$ & & & \\
\hline
\end{tabular}




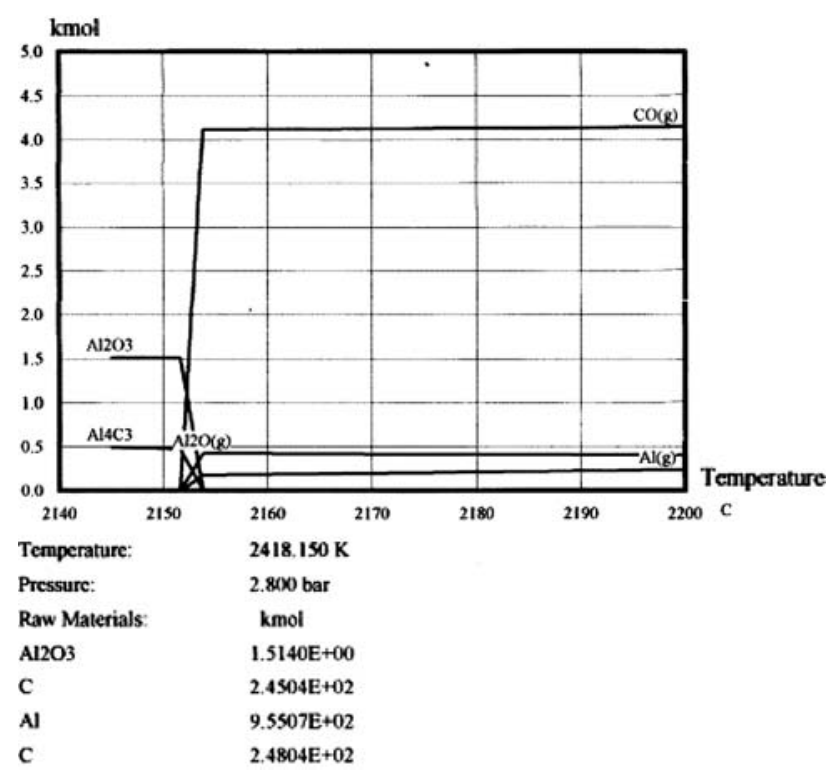

Fig. 1-Computer-generated (HSC4) equilibrium diagram for a MPR reaction zone.

MPR at just under $2200{ }^{\circ} \mathrm{C}$ and, due to extensive backmixing, dropping almost immediately to the uniform reaction temperature of $2160{ }^{\circ} \mathrm{C}$. This temperature drop takes into account not only the sensible heat transferred but also the chemical regular-solution thermal consequences of the melt-saturation carbon content dropping from saturation at $2200{ }^{\circ} \mathrm{C}$ to saturation at $2160{ }^{\circ} \mathrm{C}$. The solid feed in this example is preheated to $1950{ }^{\circ} \mathrm{C}$, and, although the basis for the evaluation is the steady-state formation of $2 \mathrm{~mol} \mathrm{Al}$ from 1 mol new calcined $\mathrm{Al}_{2} \mathrm{O}_{3}$ in the feed, the actual input to the reaction zone evaluated is $1.514 \mathrm{~mol} \mathrm{Al}_{2} \mathrm{O}_{3}$, which reflects the sum of the new feed $\mathrm{Al}_{2} \mathrm{O}_{3}$ plus that reverted via the chemical reactions occurring in the quench zone involving $\mathrm{Al}_{2} \mathrm{O}_{(g)}$ and $\mathrm{Al}_{(g)}$ with $\mathrm{CO}_{(g)}$ as the temperature decreases.

The total endothermicity to be supplied by conductive heating in the external melt-circulation loops includes not only the increase in the sensible heat but also that associated with the additional carbon dissolving in the melt to maintain saturation as the temperature increases up to just below $2200{ }^{\circ} \mathrm{C}$. Again, thermodynamic regular-solution behavior can be assumed, but, of course, this heat of solution added to the melt in the pipe heaters is returned to the system when the circulating slurry enters the MPR. Thus, the heat-ofsolution effect decreases the actual maximum temperature of the melt required in the external pipe heaters. In other words, without the beneficial effect of the heat of solution and a total reliance on sensible heat, supplying the endothermicity would require a greater temperature differential, $\Delta T$. This means that, rather than a $\Delta T$ of $50{ }^{\circ} \mathrm{C}$ being required on sensible heat grounds alone, a $\Delta T$ of approximately $40^{\circ} \mathrm{C}$ is adequate.

The HSC evaluation shown in Table I gives the endothermicity of the chemical reactions taking place in the reaction zone as being $2047 \mathrm{~kJ}$. Downstream from the chemical reaction zone, further thermal demands have to be added to this figure when evaluating total energy requirements. These are the following: (1) within the decomposer sump, $\mathrm{Al}_{4} \mathrm{C}_{3}$ coated pellets are returned to the melt at $2050{ }^{\circ} \mathrm{C}$ and the graphite pellets are subsequently removed at $2160{ }^{\circ} \mathrm{C}$, which consumes about $64.8 \mathrm{~kJ} / 2 \mathrm{~mol} \mathrm{Al}$; and (2) the addition of fine carbon particles preheated to $2000^{\circ} \mathrm{C}$, which are further heated to $2160{ }^{\circ} \mathrm{C}$ by the melt with a thermal demand of $12.0 \mathrm{~kJ} / 2 \mathrm{~mol} \mathrm{Al}$. These additional thermal loads must be added to the chemical reaction endothermicity of $2047 \mathrm{~kJ}$ shown in Table I, to give a total demand of $2124 \mathrm{~kJ} / 2 \mathrm{~mol} \mathrm{Al}$.

In fully backmixed reactor systems, such as those discussed by the author for the coproduction of steel and titanium in melt-circulation loops of "swimmingpool" dimensions, ${ }^{[7]}$ it is feasible to conduct very-hightemperature processes close to thermodynamic equilibrium such that the melt phases involved can be contained within unmelted shells of material of the solidus composition, to provide permanent linings, which can be replenished at will, with minimal disruption to operation. Clearly, this approach is not an option for melts comprised of aluminum, which has a melting point of $660{ }^{\circ} \mathrm{C}$.

The carbothermic reduction of alumina thus requires the introduction of a totally new approach. It recognizes that graphite/carbon reactors can be based reliably on simple kinetic factors at very high temperatures, where transport phenomena are all important. The stability of the graphite/carbon containment in contact with nearto-carbon-saturated aluminum melts is ensured by providing a very much more favorable diffusion-controlled alternative to graphite/carbon wall dissolution. This guarantees an operation very close to carbon saturation without ever putting the wall at risk, and is readily available to turbulent melt-circulation systems. The melt being circulated is no longer a single-liquid phase but rather a homogenous two-phase solid/liquid system or slurry in which the dispersed solid particles, graphite or carbon in the liquid aluminum case, remain in suspension throughout the reaction system. The concentration and particle size of the dispersed solid are vitally important, and it is essential that the relative rates of dissolution of particles to wall material strongly favor particle dissolution, making attack on the wall virtually negligible.

El-Kaddah and Chang ${ }^{[8]}$ evaluated the viscosity of high-volume-percentage dispersions (up to 18 vol pct) of silicon carbide fine particles ( 25 to $105 \mu \mathrm{m}$, with an average of $50 \mu \mathrm{m}$ ) in molten aluminum. Measured viscosities at $850^{\circ} \mathrm{C}$ were well represented by Einstein's theoretical equation. At 10 vol pct of dispersed particles, the relative viscosity increased to only about 1.3 times that of the pure liquid. Accordingly, the adoption of, for example, a 10 vol pct dispersion of fine carbon particles in liquid aluminum as the circulating melt is seen not to introduce any problems, in terms of flow characteristics or dispersion stability.

Alumina solid feed to the pressurized MPR is comprised of refined alumina such as "sandy" Bayer alumina $(90$ pet $+45 \mu \mathrm{m})$ and reverted $\mathrm{Al}_{2} \mathrm{O}_{3}$ recovered on cooling the MPR off-gas. There would appear to be strong parallels between the projected functioning of the MPR and a process for the gasification of coal in a 
liquid iron bath, as reported by Barin et al. ${ }^{[9]}$ The kinetics of the gasification process were investigated by analyzing and assessing the basic reactions for a bottomblowing reactor. The bath turbulence induced by the injected gas and by the product gas results in the intense mixing and dispersion of the reactants and their intermediate products. The authors point out that these phenomena create extremely large mass-transfer areas and extend the retention time of the reactants in the liquid iron bath, resulting in high conversion rates relative to the volume of the reactor. The author reaches the same conclusion for the complex physical interactions pertaining to the MPR. The prevailing turbulence will cause liquid $\mathrm{Al}_{2} \mathrm{O}_{3}$ to be transported into the bulk liquid, facilitating the key metal-producing reaction between the $\mathrm{Al}_{2} \mathrm{O}_{3}$ and the carbon dissolved in the liquid aluminum by Reaction [1]:

$$
\mathrm{Al}_{2} \mathrm{O}_{3}+3 \underline{\mathrm{C}}=2 \mathrm{Al}+3 \mathrm{CO}_{(g)}
$$

Coupled with the turbulence induced by forced melt circulation, it is the evolution of 3 moles of product gas $\left(\mathrm{CO}_{(g)}\right)$ per mol $\mathrm{Al}_{2} \mathrm{O}_{3}$ that ensures an exceptionally high degree of turbulence, as the chemistry involved is likely to be extremely rapid at $2160{ }^{\circ} \mathrm{C}$. In the coal gasification process, liquid ferrous oxide $(\mathrm{FeO})$ is formed as an intermediate in the injection zone; it is subsequently widely dispersed in the liquid iron bath and rapidly decomposed by dissolution and by subsequent reactions with dissolved carbon. Exactly the same arguments apply to aluminum metal production in the MPR. Intense bath movement can be expected, resulting in the dispersion of carbon particles and liquid $\mathrm{Al}_{2} \mathrm{O}_{3}$, thus producing emulsion and foam states, all of which result in the significant enhancement of mass-transfer rates in the liquid metal.

Gases leaving the MPR react on cooling to generate elemental carbon and, initially, a fine mist or aerosol of liquid $\mathrm{Al}_{2} \mathrm{O}_{3}$, according to Eqs. [2] and [3]:

$$
\begin{gathered}
\mathrm{Al}_{2} \mathrm{O}_{(g)}+2 \mathrm{CO}_{(g)}=\mathrm{Al}_{2} \mathrm{O}_{3}+2 \mathrm{C} \\
2 \mathrm{Al}_{(g)}+3 \mathrm{CO}_{(g)}=\mathrm{Al}_{2} \mathrm{O}_{3}+3 \mathrm{C}
\end{gathered}
$$

A serious accretion-formation problem is inevitable if the gases are allowed to contact solid walls before the aerosol solidifies and cools enough to render the solid material nonsticky. This type of problem is well recognized in other high-temperature processes; one established method for dealing with it is to employ what are termed "fluid-wall" configurations. For example, Weimer et al. ${ }^{[10]}$ advocate that to combat deposition on reactor walls and plugging of the reactor leading to eventual shutdown of the process, the inside wall is at least partially fabricated with a porous refractory material through which a compatible fluid-wall gas is forced to flow inward. This provides a blanket of gas that prevents the deposition of particles on the inside wall.

In the present case, the reactor off-gas needs to be quenched from temperatures as high as $2160{ }^{\circ} \mathrm{C}$ down to around $1950{ }^{\circ} \mathrm{C}$. This requires a substantial amount of quench gas to be forced through a porous wall and, thus, the adverse energy consumption associated with the required pressure drop to overcome friction. The undue energy consumption is exacerbated by the exothermicity of Reactions [2] and [3]. Accordingly, fluidwall configurations are not tenable and a more direct methodology is required. The off-gas is forced to leave the reactor upward as a turbulent axisymmetric jet that entrains cooled quench gas in a chamber or plenum containing the lower-temperature quench gas. The refractory walls are well removed from the jet until the temperature is reduced by entrainment and sufficient residence time is given for the aerosol liquid particles to solidify and become nonsticky. The fundamental aspects for this approach are covered in the now classic work of Ricou and Spalding, ${ }^{[11]}$ who quantified entrainment by axisymmetric turbulent jets.

Attention has been drawn in patent literature ${ }^{[12]}$ to problems associated with liquid aluminum contaminated with aluminum carbide $\left(\mathrm{Al}_{4} \mathrm{C}_{3}\right)$. It is stated: “...a primary difficulty in the carbothermic production of aluminum is caused by the substantial solubility of the carbon in the metal, about 20 atom $\% \mathrm{C}$, when the metallic melt is in equilibrium with solid carbon." It is further stated: ".... a severe practical difficulty arises in attempting to purify aluminum contaminated with $\mathrm{Al}_{4} \mathrm{C}_{3}$ in significant amounts, because the mixture becomes non-pourable unless extremely high temperatures are maintained. Accordingly, aluminum scrap is added as solid coolant to reduce the temperature from above $2000{ }^{\circ} \mathrm{C}$ down to about $900{ }^{\circ} \mathrm{C}$ to $1000{ }^{\circ} \mathrm{C}$." $\mathrm{By}$ this treatment, it is claimed that $\mathrm{Al}_{4} \mathrm{C}_{3}$ is precipitated and removed by filtration, decanted, or fluxed with a salt, to yield an aluminum metal product containing $5 \mathrm{wt}$ pct or less $\mathrm{Al}_{4} \mathrm{C}_{3}$. However, this level of residual $\mathrm{Al}_{4} \mathrm{C}_{3}$ is unacceptable if a refined grade of aluminum metal product is desired. An alternative approach would be to begin overcoming the problem at its source, i.e., while the molten aluminum is still at an extremely high temperature.

An analogous approach to a nickel carbonyl pellet decomposer is proposed for decarbonization of the melt. Carbon-saturated aluminum, if contacted with slightly cooler graphite pellets countercurrently as the continuous phase moving upward in a packed bed of pellets moving slowly downward with the melt, will deposit carbon initially on the pellets. Then $\mathrm{Al}_{4} \mathrm{C}_{3}$ will be deposited as the aluminum melt is cooled to the temperature at which $\mathrm{Al}_{4} \mathrm{C}_{3}$ becomes thermodynamically stable, provided homogeneous nucleation is avoided and heterogeneous diffusional growth is promoted. By the time the melt discharges from the top of the moving packed-bed reactor, a very-low-carbon aluminum product is assured.

Figure 2 identifies the locations of the various gas and entrained solid streams listed in Table II, which have been the subject of HSC4 equilibrium calculations with energy and materials balances. The hot gas emerging from the MPR is A and the preheated solids comprised of calcined alumina and reverted $\mathrm{Al}_{2} \mathrm{O}_{3}$, along with elemental carbon arising principally from reactions in 
the quench zone, is B. The streams B to D emerging from the cyclones with a relatively high content of solids, in comparison with the very dilute suspended solid/gas within the entrained contactors, are considered to be in thermal and chemical equilibrium with the cleaned gas leaving the cyclones E to G. The initial feed of calcined alumina is introduced at $\mathrm{H}$ via a screw feeder or similar device from a pressure-lock hopper system. Streams B to D flow opposed to the static pressure gradient and thus require the use of loop or siphon seals or similar devices. The exit gas $\mathrm{G}$ finally leaving the system goes to a heat-recovery steam generator (HRSG) before being filtered. Some of the gas is recycled for entrainment into the turbulent axisymmetric jets leaving the MPR. The balance of the gas proceeds to a shift reactor in advance of the combustor of a gas turbine for combined-cycle power generation, involving a second HRSG, probably based on supercritical steam generation, for addition to that from the other HRSG and elsewhere in the heat-recovery circuit.

The plant shown in Figure 3 employs a single-slot jet and quench-gas plenum, which services the entire MPR. The two straight-line pipe heaters are placed one on each side of the MPR, with both ends of the pipe heater being connected via a snorkel to a melt pool containing

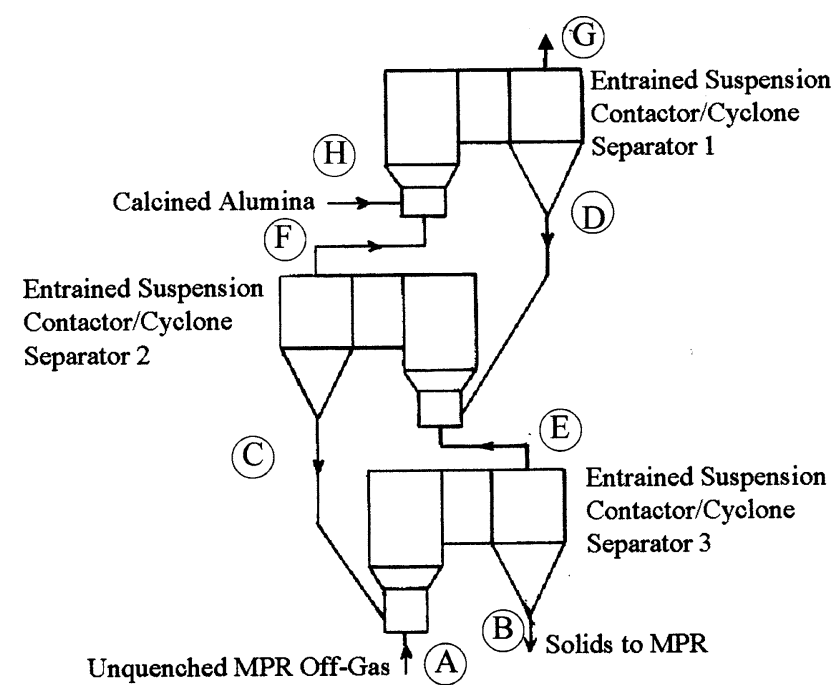

Fig. 2-Arrangement of process streams in MPR off-gas heat recovery and alumina preheating. the slurry of fine carbon particles dispersed in carbonsaturated aluminum, in order to respond to the thermal expansion of the pipe heaters and permit free movement of the snorkel within the melt pool. This arrangement also looks after any differential thermal expansion between the pipe heaters and the principal flow circuit comprised of the MPR and its ancillaries. Electric current is introduced into the pipe heater via a hub. Melt circulation is provided by four stages of gas-lift pumping in this example, and make-up fine carbon particles are drawn down into the circulating melt slurry with the assistance of impellers.

Referring to Figure 4, in this particular case, multiple units comprised of a Venturi-type entrained suspension contactor and an adjacent cyclone separator are spaced along an extended reaction zone within the MPR to quench the off-gas while affecting the preheating of solids. These solids discharge directly into the MPR reaction zone via loop seals or similar devices located at the base of each cyclone separator. The MPR is provided with two pipe heaters, one on each side of the MPR, to satisfy the thermal demands of the smelting reduction reaction occurring in the MPR reaction zone. As in Figure 3, the electrical current is introduced into the pipe heaters via hubs (not shown). Melt circulation is provided by four stages of gas-lift pumping and the make-up fine carbon is impeller assisted, drawn down into the circulating melt. Differential expansion is accommodated in the melt pool at each end of the pipe

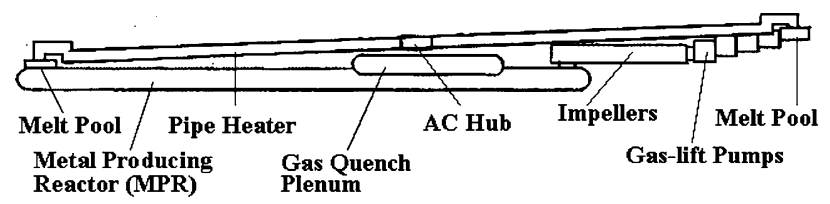

Elevation

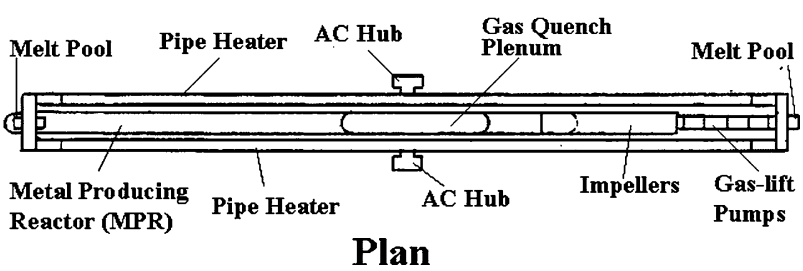

Fig. 3-Plant for production of aluminum in a single pressurized MPR employing a single-slot jet and gas-quench plenum.

Table II. Energy Recovery/Alumina Preheating; HSC4 Equilibrium Evaluation for 2.8-Bar Operating Pressure; Basis: 1 Mole $\mathrm{Al}_{2} \mathrm{O}_{3}$ Consumed or Production of 2 Moles Al (54 Grams)

\begin{tabular}{|c|c|c|c|c|c|c|c|c|}
\hline $\begin{array}{l}\text { Position as per } \\
\text { Fig. } 12\end{array}$ & $\begin{array}{c}\text { A } \\
\text { MPR } \\
\text { Off-gas }\end{array}$ & $\begin{array}{c}\text { B } \\
\text { Solids to } \\
\text { MPR }\end{array}$ & $\mathrm{C}$ & $\mathrm{D}$ & $\mathrm{E}$ & $\mathrm{F}$ & $\begin{array}{c}\mathrm{G} \\
\text { Gas to } \\
\text { HRSG }\end{array}$ & $\begin{array}{c}\mathrm{H} \\
\text { Calcined } \\
\mathrm{Al}_{2} \mathrm{O}_{3}\end{array}$ \\
\hline Temperature & $2160^{\circ} \mathrm{C}$ & $1950{ }^{\circ} \mathrm{C}$ & $1320^{\circ} \mathrm{C}$ & $746^{\circ} \mathrm{C}$ & $1950^{\circ} \mathrm{C}$ & $1320^{\circ} \mathrm{C}$ & $746^{\circ} \mathrm{C}$ & $100{ }^{\circ} \mathrm{C}$ \\
\hline $\mathrm{CO}_{(g)}(\mathrm{mol})$ & 4.121 & - & - & - & 12.924 & 13.058 & 12.583 & - \\
\hline $\mathrm{CO}_{2(g)}(\mathrm{mol})$ & $4.81 \times 10^{-5}$ & - & - & - & $3.57 \times 10^{-4}$ & $1.13 \times 10^{-2}$ & $2.49 \times 10^{-1}$ & - \\
\hline $\mathrm{Al}_{2} \mathrm{O}_{(g)}(\mathrm{mol})$ & $4.211 \times 10^{-1}$ & 一 & - & - & $6.05 \times 10^{-3}$ & $2.13 \times 10^{-14}$ & 0 & - \\
\hline $\mathrm{Al}_{(g)}(\mathrm{mol})$ & $1.860 \times 10^{-1}$ & - & - & - & $7.26 \times 10^{-3}$ & $1.05 \times 10^{-11}$ & 0 & - \\
\hline $\mathrm{Al}_{2} \mathrm{O}_{3}(\mathrm{~mol})$ & - & 1.514 & 1.010 & 1.000 & - & - & - & 1.000 \\
\hline $\mathrm{Al}_{4} \mathrm{C}_{3}(\mathrm{~mol})$ & - & $5.24 \times 10^{-5}$ & 0 & 0 & - & - & - & - \\
\hline $\mathrm{C}(\mathrm{mol})$ & - & 1.189 & 0.271 & 0.237 & - & - & - & - \\
\hline
\end{tabular}




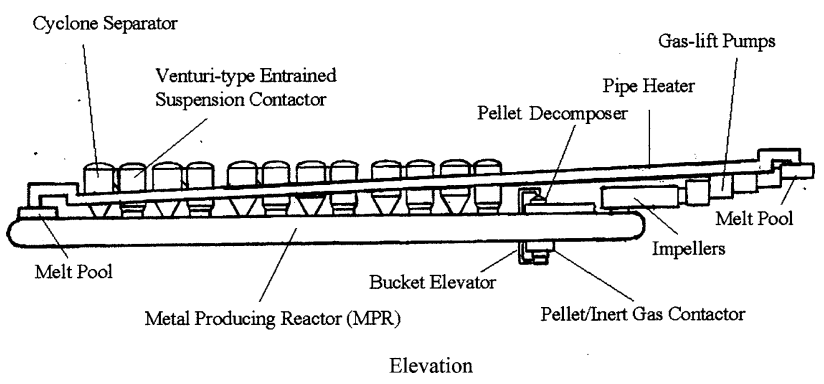

Fig. 4-Plant for production of aluminum in a single pressurized MPR employing multiple units of Venturi-type entrained suspension contactors/cyclone separators.

heaters. In this example, decarbonization of the carbonsaturated melt is effected by a pellet decomposer, with heat recovery from the carbon or graphite pellets being conducted in a moving packed-bed/inert-gas contactor from which the pellets are recirculated to the top of the pellet decomposer by a bucket elevator.

Both Figures 3 and 4 reflect what is envisaged as required for a single production line or strand that by itself should be capable of producing nominally 1 million tonnes per annum (1 Mtpa) Al. To balance the electrical load, three such strands would probably be installed in an aluminum smelting complex producing 3 Mtpa Al by the carbothermic reduction of calcined alumina. There are indisputable trends in the worldwide aluminum industry that primary aluminum plants of the future will be of the sort that will increase output, to effect economies of scale.

\section{PROCESS-ENGINEERING CONSIDERATIONS}

\section{A. Electrical Conductive Heating}

By analogy with published data on iron-carbon melts, the low resistivity of aluminum is increased only marginally by saturation with carbon. From the outset, recognition of the implications of this for electrical conductive heating must be acknowledged in process design; it has to be accepted that the "footprint" for a commercial plant will reflect this situation.

Provided proximity to equilibrium can be maintained, there will be no alumina slag present to attack graphite linings in the MPR and its associated graphite pipe meltcirculation loops. As the sole energy input is conductive heating from hydro, nuclear, or geothermal power, all attention must be focused on the dissolution of graphite walls and hearths by molten carbon-containing aluminum. In theory, provided the overall system is fully backmixed and essentially isothermal in operation, carbon saturation is a realistic target.

However, to transmit sensible heat into the reactor, a finite temperature difference needs to be established between the liquid melt entering the external loops and that returning to the MPR. A temperature differential of $40{ }^{\circ} \mathrm{C}$ has been chosen in this article for a preliminary engineering evaluation before optimization studies are attempted. Clearly, the smaller this temperature difference is in practice, the less the risk is that carbon dissolution can threaten the nominally permanent graphite reactor containment structures.

\section{B. Protection of Graphite Pipe and Wall Surfaces}

The use of fine carbon in addition to recirculated carbon particles, up to, for example, $0.05 \mathrm{~mm}$ in diameter, is believed to offer a reliable mechanism to secure virtually permanent graphite reactor walls. Kimura et al. ${ }^{[13]}$ have shown that methane decomposition initially produces particles in the 50 -to- $100-\mathrm{nm}$ region; these particles are normally loosely agglomerated in manufactured carbon black. If such an ultrafine material in an agglomerated form is dispersed into the melt, any departure from saturation is rapidly made up by particle dissolution, as opposed to the dissolution of graphite wall surfaces. Since the dissolution of carbon in molten aluminum at very high temperatures is controlled exclusively by liquid-phase diffusion, the mass-transfer coefficient applicable to individual spherical particles can be quantified. It is determined by the Ranz-Marshall equation given in Eq. [4], in terms of the dimensionless groups Sh, Re, and Sc assembled from the following variables: mass-transfer coefficient $k_{c}$, chemical diffusion coefficient or interdiffusivity $D_{\mathrm{C}-\mathrm{Al}}$, particle diameter $d_{p}$, together with liquid velocity $v$, density $\rho$, and viscosity $\mu$. The Sherwood number $\mathrm{Sh}=k_{c} D_{\mathrm{C}-\mathrm{Al}} / d_{p}$, the Reynolds number $\operatorname{Re}=d_{p} v \rho / \mu$, and the Schmidt number $\mathrm{Sc}=$ $\mu / \rho D_{\mathrm{C}-\mathrm{Al}}$.

$$
\mathrm{Sh}=2+0.6 \mathrm{Re}^{1 / 2} \mathrm{Sc}^{1 / 3}
$$

For the relatively small velocity differences anticipated between the carbon particles and melt, the masstransfer rate for fine carbon particles is characterized by $\mathrm{Sh}=2=k_{c} d_{p} / D_{\mathrm{C}-\mathrm{Al}}$, where $k_{c}$ is the mass-transfer coefficient, $d_{p}$ is particle diameter, and $D_{\mathrm{C}-\mathrm{Al}}$ is the diffusivity of carbon in the melt. The corresponding mass-transfer equation for the dissolution of carbon at the walls under turbulent flow with $\operatorname{Re}>10,000$ is given by Eq. [5]:

$$
\mathrm{Sh}=0.023 \mathrm{Re}^{0.8} \mathrm{Sc}^{1 / 3}
$$

At ambient pressure, graphite will sublime when heated rather than melt. However, at a sufficiently high temperature and pressure, graphite melts in preference to vaporizing. To explain their experimental observations, Steinbeck et al. ${ }^{[14]}$ state that liquid carbon is a liquid metal, a conclusion reached from the large thermal conductivity required for liquid carbon to account for the depth of the melt observed in pulsedlaser-heated graphite. The necessary thermal conductivity is nearly an order of magnitude larger than the in-plane component of the thermal conductivity of graphite at the same temperature. Their model calculations yield a density of $2700 \mathrm{~kg} / \mathrm{m}^{3}$ for liquid carbon.

Since Steinbeck et al. ${ }^{[14]}$ state that when graphite melts it forms what can be considered a metallic liquid, the diffusion process involved in graphite wall dissolution can be evaluated using Eq. [6], as given by Turkdogan ${ }^{[15]}$ for interdiffusion in binary metallic solutions. The term $D$ is the interdiffusivity or chemical 
diffusion coefficient applicable to a given solution at a specified composition and constant temperature.

$$
D=\left(c_{1} \underline{V}_{1} D_{2}^{*}+c_{2} \underline{V}_{2} D_{1}^{*}\right)\left(\partial \ln a_{2} / \partial \ln c_{2}\right)
$$

where $D_{1}^{*}$ and $D_{2}^{*}$ are self-diffusivities of components 1 and $2, c_{i}$ is the concentration per unit volume, and $\mathrm{V}_{i}$ is a partial molar volume and the thermodynamic activity. Turkdogan makes the substitution given in Eq. [7]:

$$
\partial \ln a_{2} / \partial \ln c_{2}=\left[1+\left(\partial \ln \gamma_{2} / \partial \ln x_{2}\right)\right]
$$

where $x_{2}$ is the atom fraction and $\gamma_{2}$ the activity coefficient of component 2. Solution thermodynamic data are not available for the Al-C system; therefore, for general use, Eq. [6] cannot be evaluated rigorously. Close to saturation, however, the activity coefficient remains unchanged, with a value of 5.61 at $2185^{\circ} \mathrm{C}$, estimated from the Al-C phase diagram given by Qiu and Metselaar. ${ }^{[4]}$ Accordingly, for the present purposes, since $\partial \ln \gamma_{2} / \partial \ln x_{2} \rightarrow 0$ near carbon saturation, the differential term in Eq. [7] is put equal to unity. With this simplification, Eq. [8] was used to evaluate the appropriate diffusivity:

$$
D_{\mathrm{C}-\mathrm{Al}}=C_{\mathrm{Al}} \underline{V}_{\mathrm{Al}} D_{\mathrm{C}}^{*}+C_{\mathrm{C}} \underline{V}_{\mathrm{C}} D_{\mathrm{Al}}^{*}
$$

The self-diffusivity of aluminum has been evaluated by Cherne III and Deymier, ${ }^{[16]}$ using the technique of equilibrium molecular dynamics, to be about $7.1 \times 10^{-5} \mathrm{~cm}^{2} / \mathrm{s}$ at the melting point, with an activation energy of $-21.33 \mathrm{~kJ} / \mathrm{mol}$ and the pre-exponential factor $1.16 \times$ $10^{-7} \mathrm{~cm}^{2} / \mathrm{s}$, which gives $D_{\mathrm{Al}}^{*}=4.08 \times 10^{-8} \mathrm{~m}^{2} / \mathrm{s}$ at $2185{ }^{\circ} \mathrm{C}$. Lu et al. ${ }^{[17]}$ in their assessment of the temperature dependence of the self-diffusion coefficients of several liquid metals, have recently pointed out that the number of systems investigated experimentally is quite small and is usually restricted to very small temperature ranges, whereas their molecular dynamic (MD) simulation ranges from the melting point to the boiling point. In conjunction with the Cherne III and Deymier figures at the melting point, the $\mathrm{Lu}$ et al. approach gives $D_{\mathrm{A} 1}^{*}=4.14 \times 10^{-8} \mathrm{~m}^{2} / \mathrm{s}$ at $2185^{\circ} \mathrm{C}$. This is the selfdiffusivity figure ultimately chosen by the author for the calculation of the chemical diffusivity figure applicable to the new process, because the extrapolation of the Arrhenius relationship proposed by Cherne III and Deymier was considered rather excessive.

Density measurements have been reported by SarouKanian et al. ${ }^{[18]}$ for aluminum in the range 1600 to $2360 \mathrm{~K}$, so only a minor extrapolation to $2458 \mathrm{~K}$ was necessary in order to obtain a density figure for pure aluminum of $1945 \mathrm{~kg} / \mathrm{m}^{3}$. When experimental solution densities are not available, as indeed is the case for solutions containing carbon and aluminum at around $2200{ }^{\circ} \mathrm{C}$, recourse has to be made to ideal mixing behavior. This is tantamount to substituting the specific molar volumes of the pure components as the partial molar quantities throughout the entire composition range. If the density of liquid carbon is $2700 \mathrm{~kg} / \mathrm{m}^{3}$ and that of liquid aluminum $1945 \mathrm{~kg} / \mathrm{m}^{3}$, the ideal mixing specific volume for a solution containing $0.178 \mathrm{~mol}$ fraction $\mathrm{C}$ and $0.822 \mathrm{~mol}$ fraction $\mathrm{Al}$ is $0.0122 \mathrm{~m}^{3} / \mathrm{kmol}$, and the concentrations of $\mathrm{C}$ and $\mathrm{Al}$ are 14.95 and $67.38 \mathrm{kmol} / \mathrm{m}^{3}$, respectively. The specific molar volumes for the pure components are $4.44 \times 10^{-3} \mathrm{~m}^{3} / \mathrm{kmol}$ for $\mathrm{C}$ and $0.0139 \mathrm{~m}^{3} / \mathrm{kmol}$ for Al. The interdiffusivity or chemical diffusion coefficient from Eq. [8] is

$$
\begin{aligned}
& D_{\mathrm{C}-\mathrm{Al}}=(67.38)(0.0139) D_{\mathrm{C}}^{*} \\
&+(14.59)\left(4.44 \times 10^{-3}\right) D_{\mathrm{Al}}^{*} \\
& D_{\mathrm{C}-\mathrm{Al}}= 9.24 \times 10^{-8}+2.69 \times 10^{-9} \\
& D_{\mathrm{C}-\mathrm{Al}}=9.51 \times 10^{-8} \mathrm{~m}^{2} / \mathrm{s}
\end{aligned}
$$

A key result in the development of these equations is the relative significance of the two self-diffusivities. Clearly, estimation of the carbon self-diffusivity is very much more important than estimation of the aluminum self-diffusivity. In terms of the protection of carbon surfaces, the value $9.51 \times 10^{-8} \mathrm{~m}^{2} / \mathrm{s}$ for the interdiffusivity is central to the evaluation. Therefore, detailed and transparent derivation is considered justified.

The strategy of circulating a dilute dispersion of fine carbon particles can be tested by evaluating the relative dissolution rate, which is the ratio of the carbon particle dissolution to the wall dissolution. For example, consider an ideal case in which a 10 vol pct $\mathrm{C}$ particle population is maintained at steady state such that a uniform particle size of $50 \mu \mathrm{m}$ is established. The plant conditions under assessment relate to two identical parallel melt-circulation loops, each one comprised of a single straight-line graphite pipe heater $1 \mathrm{~m}$ in internal diameter and $225 \mathrm{~m}$ in length, connected at both ends to the main production line of MPR, etc., as the nonheated melt return path for both loops. For a temperature differential of $40{ }^{\circ} \mathrm{C}\left(2200{ }^{\circ} \mathrm{C}\right.$ to $\left.2160{ }^{\circ} \mathrm{C}\right)$, the total estimated melt-circulation requirement is $9.50 \mathrm{~m}^{3} / \mathrm{s}$, or $4.75 \mathrm{~m}^{3} / \mathrm{s}$ per external melt loop, giving a slurry velocity of $6.05 \mathrm{~m} / \mathrm{s}$ and $\mathrm{Re}=2.78 \times 10^{7}$. Using Eq. [5], the mass-transfer coefficient $\left(k_{c}\right)_{1}=3.80 \times 10^{-3} \mathrm{~m} / \mathrm{s}$; therefore, for the carbon wall area $A_{1}$ per loop $=706.9 \mathrm{~m}^{2}$, the carbon dissolution rate $=\left(3.80 \times 10^{-3}\right)(706.9) \Delta \mathrm{C}$, where $\Delta \mathrm{C}$ is the difference between the actual carbon concentration in the bulk of the flowing melt and the equilibrium saturation level at the wall surface. Disregarding the fact that the wall temperature will be very close to but nonetheless very slightly lower than that in the bulk of the melt, because of the heat-loss flux, the same value of $\Delta \mathrm{C}$ is also applicable to the diffusion process involved in particle dissolution. Accordingly, the relative dissolution rate is given simply by Eq. [12]:

$$
\begin{aligned}
& \text { relative dissolution rate } \\
& \quad=\left[\left(k_{c}\right)_{2} A_{2}\right] \text { particle } /\left[\left(k_{c}\right)_{1} A_{1}\right] \text { wall }
\end{aligned}
$$

For the $50-\mu \mathrm{m}$ diameter carbon particles, some $1.18 \times 10^{14}$ particles are in the control length of the $225 \mathrm{~m}$ at any instant, exposing a total surface area $A_{2}=2.12 \times 10^{6} \mathrm{~m}^{2}$ to dissolution under the diffusional driving force of $\Delta \mathrm{C}$. For $\mathrm{Sh}=2$, the mass-transfer 
coefficient $=3.80 \times 10^{-3} \mathrm{~m} / \mathrm{s}$, so the relative dissolution rate from Eq. [12] works out to 4388/1. Similarly, the relative dissolution rates for 10 - and $20-\mu \mathrm{m}$ particles are $1.1 \times 10^{5} / 1$ and $2.74 \times 10^{4} / 1$, respectively. On the other hand, if a population of soot particles $100 \mathrm{~nm}$ (i.e., $0.1 \mu \mathrm{m})$ in diameter derived from methane thermal decomposition could be maintained at steady state at the $10 \mathrm{vol}$ pct level, the relative dissolution rate would be 250,000 times as large as the figure for the $50-\mu \mathrm{m}$ particles, so these ultrafine particles would demonstrate a propensity for dissolution some $1.1 \times 10^{9}$ times that of the graphite lining constituting the wall.

Unfortunately, there is no prospect for the maintenance of ultrafine particles $0.1 \mu \mathrm{m}$ in diameter at steady state. The mass of carbon present at any instant far exceeds that consumed by chemical reaction, so the excess is repeatedly recirculated, doing useful work as a carrier of sensible heat to contribute to that required to satisfy the endothermicity of the aluminum metal production, but also giving the opportunity for particles to increase in size, mainly as a result of the carbon saturation level being higher at input to the MPR than the temperature of the backmixed MPR itself. Dissolved carbon above the saturation level is freely available for the diffusive growth of particles within the backmixed reaction zone of the MPR. Also, very fine particles will disappear first in the melt-circulation loops as the temperature of the melt is gradually increased. A detailed mathematical model of the complex interactions involved would be required to establish the actual size distribution of the steady-state population of dispersed carbon particles under proposed operating conditions.

\section{Drawing Down and Dispersion of Fine Carbon Particles}

The dispersion of very fine powder into molten metals is known to be difficult when the metal does not wet the powder. Kobashi et al. ${ }^{[19]}$ for example, state that it is impossible to incorporate $\mathrm{SiC}$ particles into molten aluminum if the particle size is less than $0.1 \mu \mathrm{m}$, whereas the dispersion of ultrafine $\mathrm{ZrC}$ was not a problem because of good wettability. However, wetting or nonwetting is only an issue for ultrafine particles. Clearly, steps must be taken so that nanosized carbon is in an agglomerated condition on initial admission to the melt circuit, with release back to discrete particles once the agglomerates have been drawn down into the turbulent flowing carbon-saturated aluminum.

A good example of how an analogous problem of dealing with nanosized particles has been overcome is to be found in the new technology for the plasma spraying of coatings derived from nanocrystalline powders (particles with grain sizes less than $100 \mathrm{~nm}$ ). Nanostructured $\left(\mathrm{Al}_{2} \mathrm{O}_{3}-13\right.$ wt pet $\left.\mathrm{TiO}_{2}\right)$ powders with mean diameters of 50 and $70 \mathrm{~nm}$, respectively, were blended by Goberman et $a l .{ }^{[20]}$ to produce a powder mixture. The mixed powders were then "reconstituted" to form agglomerates $(40$ to $70 \mu \mathrm{m})$. In other words, the outer diameters were increased 1000 times. The process of reconstitution involves the spray drying of a water slurry mixture and, in the work described by Goberman et al., subsequent heat treatment.

More recently, Chang-sheng Zhai et al. ${ }^{[21]}$ have reported rheological studies on $\mathrm{Al}_{2} \mathrm{O}_{3} /$ nano- $\mathrm{TiO}_{2}$ slurries and the characteristics of powders prepared by what they call "spray pelletization." The slurry had the lowest viscosity when the contents of dispersant and binder were a mere 0.3 and $1.0 \mathrm{wt}$ pct of the solids content. A centrifugal spray dryer conducted the reconstitution process with an inert gas inlet temperature of $320^{\circ} \mathrm{C}$ and an outlet temperature of $110{ }^{\circ} \mathrm{C}$ to $120^{\circ} \mathrm{C}$. The spray pelletization of $60 \mathrm{wt}$ pct solids slurry produced reconstituted agglomerates of spherical shape, typically about $60 \mu \mathrm{m}$ in diameter. It was stated that these were fit for the thermal spraying process without further heat treatment.

Sukawa and Iguchi $^{[22]}$ recently conducted water model experiments with poorly wetted 30 - to $50-\mu \mathrm{m}$ particles. The particles were placed uniformly on a water surface and then drawn down with two different types of impellers under various conditions. The best results were obtained in a vessel with a centrally located impeller and one cylinder partly immersed near the wall of the mixing vessel acting as a baffle. Only particles with a single density of $40 \mathrm{~kg} / \mathrm{m}^{3}$ were studied. Intuitively, it seems obvious that such low-density fine particles are inherently more difficult to draw down into water than are similarly sized nonwetted particles of carbon being dispersed into carbon-saturated aluminum, where the density difference involved is considerably smaller. The experimental results by Sukawa and Iguchi with their 30 - to $50-\mu \mathrm{m}$-diameter particles are qualitatively very similar to earlier work with very much larger floating particles with a range of densities. This earlier work was conducted in vessels of a size much closer to that envisaged for the aluminum process. Also, the earlier work had already been used successfully in the design of a commercial plant with a $50-\mathrm{m}^{3}$ vessel for the suspension of floating particles.

Various studies reviewed by Joosten et al. ${ }^{[23]}$ and Bakker and Frijlink ${ }^{[24]}$ suggest that the creation of a vortex is energetically the most efficient way of suspending floating solids. Using dimensional analysis, Joosten et al. correlated the minimum Froude number for their preferred baffle arrangement (one wide baffle), to create an eccentric vortex for drawing down floating solids according to Eq. [13]:

$$
N_{\mathrm{Fr}_{\min }}=c\left(\frac{d}{D}\right)^{p}\left(\frac{\Delta \rho}{\rho_{L}}\right)^{q}\left(\frac{h}{D}\right)^{r}\left(\frac{d_{p}}{d}\right)^{s}\left(\frac{\rho_{L} n d^{2}}{\eta}\right)^{t}
$$

Omitting those dimensionless groups, which were found to have a negligibly small influence over the range of values studied, these researchers arrived at the simpler expression given by Eq. [14]. The value of the constant used in Eq. [18] is $3.6 \times 10^{-2}$, which relates to their preferred stirrer/baffle combination (one baffle $0.2 \times 0.3$ $D)$, a four-bladed inclined-blade paddle.

$$
N_{\mathrm{Fr}_{\min }}=3.6 * 10^{-2}\left(\frac{d}{D}\right)^{-3.65}\left(\frac{\Delta \rho}{\rho_{L}}\right)^{0.42}
$$


The Froude number is defined as

$$
N_{\text {Fr }}=n^{2} d / g
$$

Equation [14] was checked over the following limits: $0.27 \leq D \leq 1.8 \mathrm{~m} ; \quad 0.29 \leq d / D \leq 0.60 ; \quad 0.1 \leq \Delta \rho / \rho_{L} \leq$ $0.76 ; \quad 0.11 \leq h / D \leq 0.33 ; \quad 2 \leq d_{p} \leq 13 \mathrm{~mm}$, and for $\eta=10^{-3} \mathrm{Ns} / \mathrm{m}^{2}$ and $\rho_{L}=1000 \mathrm{~kg} / \mathrm{m}^{3}$,

where

$$
\begin{aligned}
& c=\text { constant } \\
& D=\text { vessel diameter } \\
& d=\text { stirrer diameter } \\
& d_{p}=\text { particle diameter } \\
& \mathrm{Fr}=\text { dimensionless Froude Number } \\
& g=\text { acceleration due to gravity } \\
& h=\text { height of stirrer above the bottom } \\
& n=\text { number of stirrer revolutions per second } \\
& \eta=\text { liquid viscosity } \\
& \rho_{L}=\text { liquid density } \\
& \Delta \rho=\text { density difference between liquid and solid } \\
& p, q, r, s, \text { and } t=\text { constants }
\end{aligned}
$$

The critical Froude number identified by Joosten et al. ${ }^{[23]}$ relates to the minimum stirrer speed at which stagnant zones of floating solids at the liquid surface had just disappeared. For the work reported by Bakker and Frijlink ${ }^{[24]}$ a just-suspended state was defined as that in which no particles stayed on the surface for longer than 1 second. In their work, $0.1 \mathrm{~kg}$ of solid material was added, resulting in a floating layer on the liquid surface between 1 and 2 particle diameters high. Although these experiments were conducted batchwise, to a first approximation they can reasonably be considered to be indicative of the behavior for the continuous draw down of particles with a solids feed rate of $0.1 \mathrm{~kg} / \mathrm{s}$.

According to the simplified empirical relationship given by Eq. [14], the only significant dimensionless group that needs to be taken into account in moving from a water model study to the high-temperature system under discussion is $\left(\frac{\Delta \rho}{\rho_{L}}\right)$, provided the appropriate constant in Eq. [14] tabulated in Joosten et al. ${ }^{[23]}$ is used for the particular type of impeller and baffle system employed. On this basis, experimental data reported by Bakker and Frijlink ${ }^{[24]}$ for their 1.2-m-diameter vessel with a liquid volume of $1.36 \mathrm{~m}^{3}$, stirred by an inclinedblade impeller with a 45-deg blade angle in an upward pumping mode with one wide baffle can be extended to the draw down of carbon particles in the hightemperature system. The relevant $N_{\mathrm{Fr}_{\min }}$ so evaluated for the high-temperature system is 0.342 , obtained by substituting $\left(\frac{d}{D}\right)=0.4,\left(\frac{\Delta \rho}{\rho_{L}}\right)=0.091$, and the constant $=3.3 \times 10^{-2}$ in Eq. [14].

The theoretical energy required for a given mass of material to go from an initial state of floating on a liquid surface to a final state involving dispersion in a denser liquid, if surface tension effects are unimportant, requires a certain amount of energy. Assuming that there are no major energy losses, it does not matter what intermediate route is taken to accomplish this. Also, if this involves the creation of a vortex in a vessel of given size with a liquid of specified properties and with a particular arrangement and type of impeller and baffle configuration, it should be immaterial whether this is done directly or indirectly in one step or in a number of smaller vessels, provided the initial and final states are identical.

The shaft power required to drive an agitator in an enclosed tank of liquid can, in general, be estimated using the dimensionless equation given in Eq. [16]:

$$
N_{p}=K N_{\mathrm{Re}}^{b} N_{\mathrm{Fr}}^{c}
$$

where $N_{p}=$ power number, $N_{\mathrm{Re}}=$ Reynolds number $=d^{2} n \rho / \mu$, and $K=$ a constant, dependent on the agitator type and size and the agitator-tank geometry.

At high $N_{\mathrm{Re}}, N_{p}$ is independent of $N_{\mathrm{Fr}}$ and the index $c=0$. Also, when $N_{\mathrm{Re}}$ is typically above $10^{4}, N_{p}$ reaches a constant value $P o$ given by

$$
P o=\frac{P}{\rho_{L} n^{3} d^{5}}
$$

The $P o$ is assigned a value of 1.61 by Bakker et al. ${ }^{[24]}$ for the particular stirrer system and geometry involved in their studies; because $N_{\operatorname{Re}}$ is about $10^{8}$ in the hightemperature system, the same number is clearly applicable. The substitution in Eq. [17] provides an estimate of the power required to draw down fine carbon particles into the melt at a nominal rate of $0.1 \mathrm{~kg} / \mathrm{s}$, as $1.498 \mathrm{~kW}$ for a vessel $1.2 \mathrm{~m}$ in diameter containing $1.36 \mathrm{~m}^{3}$ of carbon-saturated aluminum melt with $10 \mathrm{vol}$ pct $\mathrm{C}$ particles in suspension.

This power would actually be dissipated initially in the liquid by the creation of conditions such that at least $N_{\mathrm{Fr}_{\text {min }}}$ is established, thus allowing energy to be transferred indirectly to the solid particles being drawn down. Viewed from this perspective, if carbon particles have to be drawn down at a rate of $21.13 \mathrm{~kg} / \mathrm{s}$, a minimum power input of around (1.498)(21.13) $/ 0.1=316.5 \mathrm{~kW}$ has to be expended in stirring a vessel or vessels, in order to establish the liquid motion conditions that result in the attainment of the $N_{\mathrm{Fr}_{\text {min }}}$ criterion for the particular vessel and its contents and the configurations of impeller and baffle.

For conservative design purposes, it was decided that at least twice the critical Froude number should be aimed for and, on this basis, for 2-m-equivalentdiameter compartments arranged in line with and downstream from the MPR with 0.8-m-diameter impellers, the power input per vessel works out to $25.38 \mathrm{~kW}$ for $n=2.9 \mathrm{~s}^{-1}$, as dictated for $2 N_{\mathrm{Fr}_{\min }}$. Accordingly, the number of in-line impellers required to draw down $21.13 \mathrm{~kg} / \mathrm{s}$ of carbon particles $=316.5 / 25.38=12$ to the nearest whole number.

In summary, the objective is to provide an arrangement downstream from the MPR, which will consume at least $316.5 \mathrm{~kW}$ in establishing twice $N_{\mathrm{Fr}_{\min }}$, so that carbon solids added continuously are drawn down into the carbon-saturated aluminum. In engineering terms, the solid carbon particles need to be added via a screw feeder, for example, to a chute, so that fine carbon particles or solid agglomerates in free fall are targeted at the vortex or close thereby. A proposed design involving 
the equivalent of 12 vessels $2 \mathrm{~m}$ in diameter in series, each consuming about $25.38 \mathrm{~kW}$, should ensure adequate power input. The total power consumption is almost negligible (about $0.02 \mathrm{pct}$ ), in comparison with a total theoretical power input required for the MPR circuit involved in an aluminum production of $1 \mathrm{Mtpa}$.

To allay concern about graphite impellers rotating at $174 \mathrm{rpm}$ at, for example, $2160{ }^{\circ} \mathrm{C}$, the centrifugal tensile stress at the periphery of a 0.8 -m-diameter graphite impeller is a mere $0.088 \mathrm{MPa}$, in comparison with the short-time breaking strength of typical graphites at this temperature in the range 3500 to $5500 \mathrm{psi}$ (24 to $38 \mathrm{MPa})$, according to data given by Malmstrom et al. ${ }^{[25]}$ Accordingly, the number of stages of the impeller-assisted draw down of carbon particles can be reduced safely by a smaller number of increased-powerconsuming impellers.

Wagner et al. ${ }^{[26]}$ give the steady-state creep rate for a typical commercial graphite material by Eq. [18], which highlights the marked dependency of the creep rate $\dot{\varepsilon}\left(\mathrm{s}^{-1}\right)$ with both temperature increase and increasing stress. When considering the effect of an externally applied stress, these authors define a reduced stress $\left(\sigma / \sigma_{B}\right)$, where $\sigma$ is the applied stress and $\sigma_{B}$ is the stress necessary to fracture the particular sample at a given test temperature. They also observe that the creep rate in tension is consistent with a thermal activation process and propose a value for the activation energy. Their empirical relationship is given in Eq. [18], in which the activation energy is expressed in cal $/ \mathrm{mol}$.

$$
\dot{\varepsilon}=4\left(\sigma / \sigma_{B}\right)^{3.8} \mathrm{e}^{-69,000 / \mathrm{R} T}
$$

This relationship confirms the expectation that it is crucially important to ensure that both the temperature and the actual stress must be kept to an absolute minimum in the design.

\section{CONCEPTUAL DESIGN DETAILS}

Details will now be given of a projected plant to produce 1 Mtpa $\mathrm{Al}$, using the pressurized smelting reduction of Bayer alumina. Insofar as is possible, the fundamental foundations or proven commercial practice behind the design will be identified.

\section{A. Pressurization Aspects}

Pressurization, even to a relatively modest degree, dramatically reduces the plant footprint. The MPR pressure vessel and the pellet decomposer sump operate at 2.8 bar absolute. Barometric legs connect to other ancillary plants within the overall melt-circulation loop and are all at close-to-atmospheric pressure, including the two vitally important conductive-heating external pipe loops. This core assembly can be contained within a rectangle $16 \times 265 \mathrm{~m}$. For a three-phase-mains electricity supply, the ideal arrangement for phase balancing would clearly be three production lines in parallel, nominally occupying, for example, $50 \times 265 \mathrm{~m}$, to produce annually $3 \mathrm{Mtpa}$ Al. A plan view for $1 \mathrm{Mtpa}$ is given in Figure 3, which omits the ancillaries related to the gas quench, initial-preheating alumina and carbon, gas booster for the gas-quench recycle, and advanced power plant. Also excluded are the solidsstorage and lock-hopper feeding systems. These latter components all comprise adaptations of current commercial practice.

The large pressure vessel $6.5 \mathrm{~m}$ in diameter and around $190 \mathrm{~m}$ in length shown in Figure 3 encases a graphite rectangular channel for producing 1 Mtpa Al. This size vessel is within the bounds of established commercial practice. Refractory brick-lined rotary kilns up to $7.6 \mathrm{~m}$ in diameter by $190 \mathrm{~m}$ in length are already in existence. Approximately ten years ago, a radiant syngas cooler (RSC) was transported from Italy to Florida to be the centerpiece in the Tampa Electric Polk Power Station integrated gasification combined-cycle (IGCC) project. The trade literature gives its dimensions as $7.6 \mathrm{~m}$ in diameter by $42 \mathrm{~m}$, and weighing 470 tons. The RSC pressure vessels operate at a 32-bar pressure and are of single-shell construction with refractory lining. Conditions within a RSC are arguably very much more aggressive than in any scenario likely to be met for the MPR.

In the time since the Polk County IGCC project, further parallel developments have taken place in pressurized fluidized bed combustion (PFBC) for power generation, necessitating pressure vessels, which dwarf the RSC referred to here. For example, the Karita PFBC project in Japan commissioned in the year 2000 has a pressure vessel $16 \mathrm{~m}$ in diameter $\times 52 \mathrm{~m}$, operating at an 18-bar pressure. The norm for a PFBC is to contain the fluidized combustors freestanding within pressure vessels and to pressurize the gas space therein with air from the main air turbocompressor to exceed the pressure of the plant contained within the pressure vessel, so that external leakage cannot occur but, instead, an ingress of air takes place if a leakage develops.

\section{B. Gas-Lift Pumping}

Using gas-lift pumping, as outlined in many previous technical articles by the author, the forced circulation of carbon-saturated aluminum containing $10 \mathrm{vol}$ pct of dispersed fine carbon particles does not introduce any special problems and should be relatively straightforward. All that is needed is the creation of a homogeneous two-phase zone of inert gas/aluminum melt within a compartment formed by an underflow weir across the channel and an overflow weir adjacent to it, both constructed of graphite and each spanning across the full width of the flow path. Pumping molten aluminum using graphite-submerged centrifugal pumps or by electromagnetic means is well established in both the primary and secondary aluminum industries, so this technology is immediately available for startup purposes, switching over to gas-lift pumping at higher temperatures once the whole system is completely charged with molten aluminum and functioning according to design.

An overall melt-circulation system employing four stages of gas lift pumping is shown schematically in the sectional elevation given in Figure 5. Carbon or graphite 


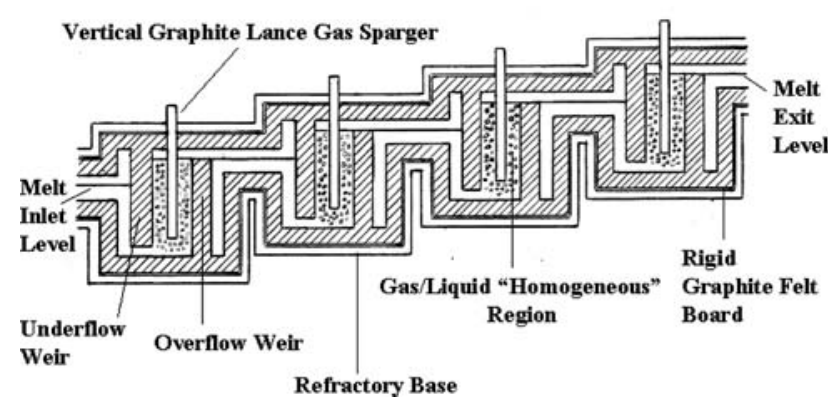

Fig. 5-Sectional elevation of a four-stage gas-lift pumping arrangement.

blocks are used to fabricate a series of underflow and overflow weirs with connecting passages arranged in series to create a multistage gas-lift pumping system. Vertical graphite lances admit inert gas to the melt at the base of the two-phase gas/liquid region, through a sparger of high permeability or a similar arrangement involving numerous small-diameter holes connected to a central pipe running the length of the lance. The arrangement employs techniques developed for the assembly of column graphite electrodes for electric arc furnaces, to provide the length needed to satisfy the submergence requirements associated with gas-lift pumping in general. Normally, submergence twice the liquid head to be developed per stage is specified.

The cross section in Figure 5 shows a single lance in each of the four two-phase compartments or regions comprised of bubbles of inert gas flowing homogeneously with the melt slurry to effect density reduction. The head developed over the four stages as illustrated, for example, is the difference in height of the melt slurry at exit level minus that at inlet. Contingent upon laboratory testing, rows of lances in addition those shown in this cross section may need to be deployed to satisfy the endothermicity of the alumina reduction to metal with a predetermined drop in slurry melt temperature.

The whole of the assembly shown in Figure 5 must be free to move to accommodate thermal expansion, so the individual stages are effectively graphite structures freestanding on refractory foundations insulated by rigid graphite felt boards, to drop the temperature from around $2160{ }^{\circ} \mathrm{C}$ to at least $1800{ }^{\circ} \mathrm{C}$ and preferably to around $1650{ }^{\circ} \mathrm{C}$ to $1700{ }^{\circ} \mathrm{C}$. To prevent oxidation of the graphite or carbon structures, the provision of a protective inert gas atmosphere is essential. Insulating refractory-lined shells (not shown) are used to limit the heat losses, but, since the maximum graphite temperature is safely below the recommended $2200{ }^{\circ} \mathrm{C}$ upper limit recommended for graphite rigid felt insulation, there is no necessity for implementing a controlled-heatloss strategy. The gas pressure is preferably slightly above the atmospheric pressure, to preclude air infiltration into the inert protective gas contained within the shell enclosure or enclosures.

To progress with the conceptual design for $1 \mathrm{Mtpa}$ $\mathrm{Al}$, an estimate of the energy consumption for melt circulation is required, but, intuitively, because of the low frictional head and relatively low melt-circulation ratio, as defined by the melt-circulation rate divided by the volumetric rate of aluminum production, the energy requirement can reasonably be expected to be minimal. The volumetric flow per loop is $4.75 \mathrm{~m}^{3} / \mathrm{s}$. There are two loops involved in the design, so the total flow is $9.50 \mathrm{~m}^{3} / \mathrm{s}$, which corresponds to about $18,860 \mathrm{~kg} / \mathrm{s}$. The total frictional loss and velocity head losses are $5.4 \mathrm{~m}$, so the theoretical work input required per second for gas-lift melt circulation is given by $W=(18,860)(5.4)(9.81)=$ $999,090 \mathrm{~J} / \mathrm{s}=1.0 \mathrm{MW}$. This corresponds to about 0.08 pct of the total theoretical power input for the process.

The actual inert gas injection from the overhead lance system shown in Figure 5 can now be specified. When inert gas (probably argon) is injected into the homogeneous two-phase flow compartment, bubbles continue downward initially and heat is transferred very rapidly. Assume that dispersed gas is virtually at bath temperature by the time bubbles begin to rise and as "hydrostatic" pressure decreases. The dispersed gas effectively expands isothermally throughout most of the two-phase gas/liquid region. The theoretical energy input per unit mass of inert gas is thus given by

$$
-W=\int_{P_{l}}^{P_{l}} P d v=\frac{\mathrm{R} T_{1}}{M} \ln \frac{P_{2}}{P_{1}}
$$

In the present case, lift-gas injection from overhead lances occurs where the pressure is 1.3 bar plus the hydrostatic pressure equivalent of, for example, a $2.7-\mathrm{m}$ submergence in the undisturbed melt prior to the gas injection, which is 0.528 bar, making the total pressure $P_{2}=1.828$ and $P_{1}=1.30 \mathrm{bar}$. The injected argon thus expands from a pressure of 1.828 bar, where, in this example, the average temperature in the pumping zone is $2160{ }^{\circ} \mathrm{C}$, to $1.30 \mathrm{bar}$; in so doing, it inputs energy into the system equivalent to $W=(8.314)(2433) \ln (1.828 /$ $1.30) /(39.95)=172.59 \mathrm{~kJ} / \mathrm{kg}$.

The $W$ input required for melt circulation $=999.1 \mathrm{~kJ} / \mathrm{s}$; the total argon flow rate needed $=$ $999.1 / 174.36 \mathrm{~kg} / \mathrm{s}=5.79 \mathrm{~kg} / \mathrm{s}=0.145 \mathrm{kmol} / \mathrm{s}$.

The thermal quench effect of this injected argon if there is no preheat, i.e., $15^{\circ} \mathrm{C}$ to $2160{ }^{\circ} \mathrm{C}$, is $6.46 \mathrm{MW}$, which is excessive, so a heat exchanger is preferably installed, not only to preheat the incoming argon but also to condense out and recover aluminum from the saturated lift gas.

\section{Melt Decarbonization}

Next to be considered is the outline design of the pellet decomposer, already referred to for decarbonization of the carbon-saturated aluminum to yield an aluminum product with a carbon content well within limits acceptable to the industry. A general arrangement is shown in Figure 6, which is a sectional elevation of the portion of the MPR between the off-gas-quench system and the barometric leg leading to the fine carbon impeller-assisted draw down. The pellet decomposer 


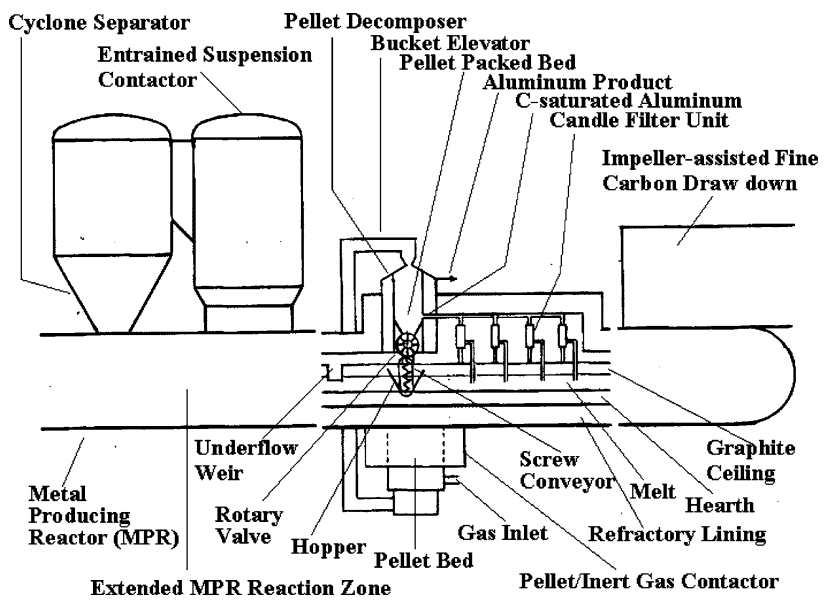

Fig. 6-Schematic half sectional elevation of portion of a MPR showing the location and general arrangement of the pellet decomposer for in-line melt decarbonization.

sump with its candle filters and the moving packed bed of densified carbon or graphite spherical pellets 1 to $5 \mathrm{~cm}$ in diameter are within the plane of the section. Carbon-saturated melt containing 10 vol pct fine carbon particles passes from the reaction zone in the MPR via an underflow weir to the sump of the pellet decomposer. This sump can be arranged so that, for example, it is maintained at a pressure of 2.8 bar with an argon gas atmosphere. It can be conveniently placed next in line in the flowpath of the principal melt circulation immediately after the MPR reaction zone within the same pressure vessel. By having the pellet decomposer sump at 2.8 bar, carbon-saturated aluminum cannot be directly separated from the $10 \mathrm{vol}$ pct of dispersed carbon particles using a candle filter. Filtration using candle filters requires infiltration of the melt into the open pore structure of the filter medium. An absolute pressure of 2.8 bar is inadequate for forcing carbon-saturated aluminum into the graphite.

The relationship between the applied pressure and the pore size into which a nonwetting liquid will intrude is given by Eq. [20], the Washburn equation, concerning the dynamics of capillary flow:

$$
P=2 \gamma \cos \theta / r
$$

where $P$ is the applied pressure, $r$ is the pore radius, $\gamma$ is the surface tension, and $\theta$ is the contact angle between the liquid and the pore wall.

In the absence of an $\mathrm{Al}_{4} \mathrm{C}_{3}$ formation, it is well known that liquid aluminum does not wet graphite. As there can be no $\mathrm{Al}_{4} \mathrm{C}_{3}$ stability at $2160{ }^{\circ} \mathrm{C}$, according to the phase diagram, it is reasonable to expect contact angles in the range $120^{\circ} \mathrm{C}$ to $140{ }^{\circ} \mathrm{C}$, as observed at low temperatures in the absence of any thin oxide skin, which hinders wetting, but before a reaction between $\mathrm{Al}$ and $\mathrm{C}$ takes place because of kinetic constraints.

Molina et al. ${ }^{[27]}$ have recently studied the infiltration of $\mathrm{Al}-\mathrm{Si}$ eutectic at $680{ }^{\circ} \mathrm{C}$ into fine-grained graphite preforms with around 10 pct open porosity, 2 pct closed porosity, a bulk density of $1830 \mathrm{~kg} / \mathrm{m}^{3}$, and a 78 pct degree of graphitization. The pressures for first penetration were reported as $0.95 \pm 0.1 \mathrm{MPa}$ for mercury and $2.3 \pm 0.2 \mathrm{MPa}$ for the Al-12 wt pet Si melt. Also, Pardini et al. ${ }^{[28]}$ have reported mercury porosimetry data for two kinds of commercial synthetic graphite: (1) extruded graphite with coarse grains, designated HLM, and (2) an isotropic compressed fine-grained graphite, designated ATJ. Porosimetry shows a 12 pct open pore structure for the HLM, with a wide size distribution ranging from 1 or 2 to $250 \mu \mathrm{m}$. The ATJ graphite, on the other hand, exhibits a more homogeneous structure and the pores are smaller, with most of them elongated. The majority of the ATJ pores are classified as mesopores in the range 1 to $10 \mu \mathrm{m}$, with an open pore structure of 8 pct. Such a material may not be porous enough for the candle filters prescribed for removing carbon particles from the carbon-saturated melt, but the pore size is suitable. Filtration would preferably be carried out immediately after the reaction zone in the MPR, the majority of carbon particles having already been exposed to intensive chemical reaction and multiple passes through the pipe heaters and, thus, subjected to the dissolution of the very finest particles initially added to the system.

The surface tension of oxygen-free liquid $\mathrm{Al}$ has been measured up to $2170 \mathrm{~K}$ by Sarou-Kanian et al..$^{[18]}$ Extrapolation of their data to $2160{ }^{\circ} \mathrm{C}$ gives a surface tension of about $637 \mathrm{mN} / \mathrm{m}$. This is appreciably higher than that of mercury at room temperature $(486 \mathrm{mN} / \mathrm{m})$, but is lower than $847 \mathrm{mN} / \mathrm{m}$ for $\mathrm{Al}-12 \mathrm{Si}$ at $680{ }^{\circ} \mathrm{C}$. Calculations based on these figures indicate that the operating pressure of the MPR is an order of magnitude or so too low for in-situ candle filtration using graphite. The melt slurry will have to be removed and then pressurized in isolation with compressed gas (probably argon) above the melt in slurry reservoirs adjacent to the candle filter units.

Candle filters are conventionally long, hollow cylinders with one end closed and with the flow inward during the filtration cycle, during which time a filter cake built is up on the external surfaces. After a prescribed time, the gas pressure is released and the filter cake removed from the candle surfaces. This can be done mechanically, so that the cake drops into a collecting hopper, where the turbulent conditions are suitable for its redispersal into the circulating melt. In common with other surface filters, candle filters are operated cyclically. A second unit is brought on stream just as soon as filtration in the first unit is terminated.

Figure 7 is a schematic diagram of an individual candle filter unit; Table III summarizes the essential features of a possible design, based on the use of the ATJ family of graphite materials. The ATJ itself has an extremely low permeability (0.002 Darcy) and is used to contain the slurry under pressure in a number of slurry reservoir and filter unit vessels, for cyclic operation. The candles themselves are fabricated from ATA, with a nominal permeability of 0.026 Darcy.

The flow of liquid aluminum through the porous graphite filter medium can be described by Darcy's Law. 
For graphite materials, Darcy's Law is customarily written in non-SI units as

$$
Q=k\left(P_{1}-P_{2}\right) A / \mu L
$$

where

$$
\begin{aligned}
& Q=\text { rate of flow }\left(\mathrm{cm}^{3} / \mathrm{s}\right) \\
& k=\text { permeability (Darcy) } \\
& \left(P_{1}-P_{2}\right)=\text { pressure drop }(\mathrm{atm}) \\
& A=\text { cross-sectional area }\left(\mathrm{cm}^{2}\right) \\
& L=\text { length in flow direction }(\mathrm{cm})
\end{aligned}
$$

In SI units, 1 Darcy is approximately $9.90 \times 10^{-13} \mathrm{~m}^{2}$.

To maintain a steady flow of the nonwetting liquid aluminum within the graphite filter medium, the local static pressure must be sufficient to overcome the capillary force of an interface at sharp discontinuities in the pore diameter. In effect, this means that at least the infiltration start pressure given by Eq. [20] must be

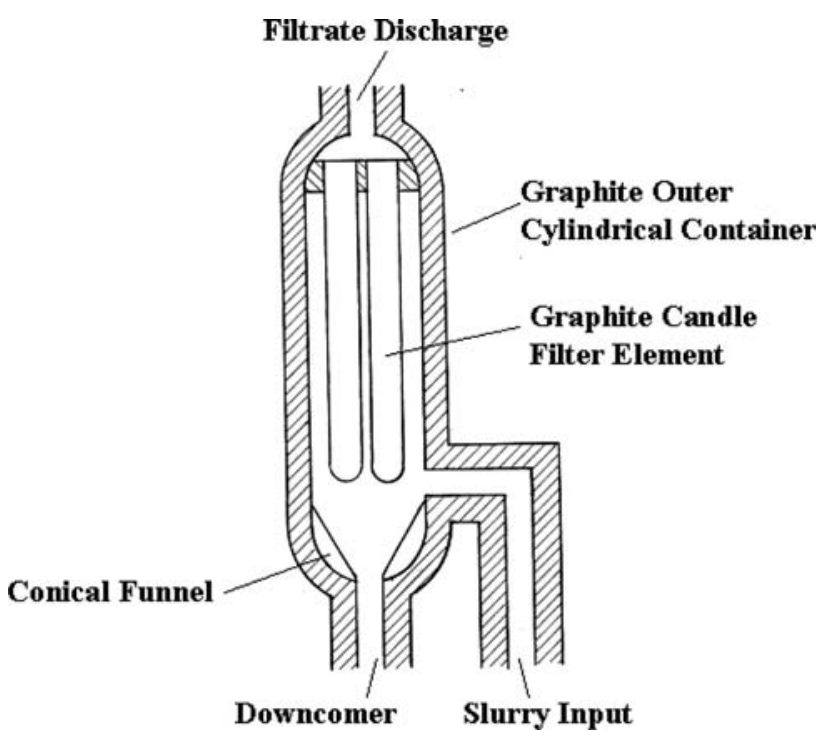

Fig. 7 - Cross-sectional elevation showing essential features of a candle filter unit. sustained throughout the passage of the aluminum through the entire width of the graphite filter medium.

The carbon particle filter cake can be regarded approximately as a packed bed of spherical particles with a permeability given using the Ergun equation, $k=d_{p}^{2} \varepsilon^{3} / 150(1-\varepsilon)^{2}$, where $\varepsilon$ is the porosity and $d_{p}$ the average particle diameter. In the present case for $d_{p}=20$ $\mu \mathrm{m}$, for example, $\varepsilon=0.30$, the permeability of the filter cake $=\left(20 \times 10^{-6}\right)^{2}(0.30)^{3} /(150)(1-0.30)^{2}=$ $1.469 \times 10^{-13} \mathrm{~m}^{2}$, or $1.469 \times 10^{-13} / 9.9 \times 10^{-13}=0.148$ Darcy. If, for example, 16 filter elements are on line at any instant (i.e., four candle filter units), the average flow through each element is then $(0.0176 /$ 16) $=1.10 \times 10^{-3} \mathrm{~m}^{3} / \mathrm{s}=1100 \mathrm{~cm}^{3} / \mathrm{s}$. From Eq. [21], the maximum pressure drop across a 2-cm-thick filter cake is $\left(P_{1}-P_{2}\right)=Q \mu L / k A=(1100)$ (0.355) (2)/ $(0.148)(5655)=0.933 \mathrm{~atm}=0.095 \mathrm{MPa}$.

Assuming that a uniform flow of filtered carbonsaturated aluminum is required for passage to the pellet decomposer and that 16 candle filter elements are on line at any instant, the maximum pressure drop required to be sustained across the graphite filter medium is the sum of the pressure drop across the filter cake plus the pressure drop across the filter medium, which by itself is $\left(P_{1}-P_{2}\right)=Q \mu L / k A=(1100)$ $(0.355(2) /(0.026)(3690)=8.141$ atm $=0.825 \mathrm{MPa}$, so the total pressure drop to be overcome $=0.825+$ $0.095=0.92 \mathrm{MPa}$. To this figure, the pressure for first infiltration must be added; it must also be born in mind that the exit static pressure of the filtered Al immediately on emergence from the filter medium must be at least equal to the first intrusion pressure. Molina et al. ${ }^{[27]}$ give the latter as $2.3 \pm 0.2 \mathrm{MPa}$ for $\mathrm{Al}-12 \mathrm{wt}$ pet $\mathrm{Si}$ at $680{ }^{\circ} \mathrm{C}$, which, using Eq. [20] to correct for the surface tensions involved, translates into $1.68 \pm 0.2$ or $\mathrm{Al}$ at $2160{ }^{\circ} \mathrm{C}$. Thus, the allowance for the overall pressure drop must be $(0.92)+(1.88)=2.8 \mathrm{MPa}$; accordingly, if the exit pressure from the filter medium must be greater than the pressure for first infiltration, the pressurization to be exerted by the compressed argon admitted to the unit $=(2.8+1.88)=4.68 \mathrm{MPa}$. The static pressure of the molten aluminum leaving the

Table III. Indicative Calculated Values for Candle Filtration; Basis: Aluminum Production 1 Mtpa

(a) Volumetric flow of melt slurry $=0.0196 \mathrm{~m}^{3} / \mathrm{s}$ at $2160{ }^{\circ} \mathrm{C}$.

(b) Volumetric flow of C-saturated $\mathrm{Al}=0.0176 \mathrm{~m}^{3} / \mathrm{s}$ at $2160{ }^{\circ} \mathrm{C}$.

(c) Pressurized slurry reservoirs and filter element containment vessels (4 candles on square pitch) fabricated from commercially available ATJ graphite rounds 24 in. in diameter $\times 72$ in. in length. Candles machined from ATA graphite.

(d) Working volume for each cylindrical reservoir vessel $=0.130 \mathrm{~m}^{3}$.

(e) Number of reservoir vessels on line at any instant $=8$.

(f) Number of candles, each $0.10-\mathrm{m}$ outside diameter by $1.5-\mathrm{m}$ effective length on line at any instant $=16$ (i.e., 4 candle filter units).

(g) Cycle time $=50 \mathrm{~s}$, which is equivalent to having available $(8 \times 0.130)=1.04 \mathrm{~m}^{3}$ of slurry for each cycle. Design requirement is $0.98 \mathrm{~m}^{3}$ for $50 \mathrm{~s}$.

(h) Reservoir vessels and candle filter unit vessels (ATJ)

(i) Design maximum tensile stress $=1294$ psi.

(ii) Estimated tensile strength at $2160{ }^{\circ} \mathrm{C}=5984 \mathrm{psi}$, based on Internet data for ATJ at room temperature given as 3470 psi and indicative 60 pct increase in strength going from room temperature to $2160{ }^{\circ} \mathrm{C}$.

(i) Candle Filter Elements (ATA)

(i) Design maximum tensile stress $=1443$ psi.

(ii) Estimated tensile strength at $2160{ }^{\circ} \mathrm{C}=4160 \mathrm{psi}$, based on Internet data for ATA at room temperature, given as 2600 psi and indicative of $60 \mathrm{pct}$ increase in strength, going from room temperature to $2160{ }^{\circ} \mathrm{C}$. 
candle filter unit assembly is still at $1.88 \mathrm{MPa}$, so release of this pressure to the required inlet pressure for melt into the pellet decomposer must be safely undertaken en route to the pellet decomposer.

Ideally, a virtually constant stream of carbon-saturated melt is forwarded to the base of the pellet decomposer. It is important to recognize that the carryover of fine particles is undesirable, because these will act as nuclei for subsequent solids deposition. Accordingly, it may be necessary to conductively heat the melt above the saturation temperature, as it proceeds to the pellet decomposer, downstream from the candle filter elements, so that a prescribed portion of any fines carryover is redissolved in the melt before entry into the decomposer.

At the base of the decomposer, substantial temperature gradients can be expected and, depending on the temperature of the external surface of the pellets, either carbon or $\mathrm{Al}_{4} \mathrm{C}_{3}$ will plate out on the pellets. Initially, some carbon may be deposited, followed by major growth of $\mathrm{Al}_{4} \mathrm{C}_{3}$ on the pellets as the temperature falls.

Recirculated graphite pellets, after thermal-energy transfer to a carrier gas, probably argon, which in turn proceeds to heat recovery involving preheating the fine carbon make-up from $100{ }^{\circ} \mathrm{C}$ to $2000{ }^{\circ} \mathrm{C}$ and some process steam generation, are fed to the top of the pellet decomposer. The $\mathrm{Al}_{4} \mathrm{C}_{3}$ coated pellets subsequently discharge from the bottom of the pellet decomposer at a temperature of $2050{ }^{\circ} \mathrm{C}$ into the sump via a rotary feeder. This feeder will be constructed entirely of graphite or a carbon-fiber-reinforced carbon composite; since it is in contact with fully carbon-saturated aluminum melt, it should be adequately protected.

As shown in Figure 8, which is a schematic crosssectional end elevation of that shown in Figure $6, \mathrm{Al}_{4} \mathrm{C}_{3}$ coated pellets and the associated melt from the rotary feeder discharge in free fall into the gas space in the decomposer sump. Throughout the preceding unit operations, the melt remains the continuous phase until discharge into the sump by the rotary feeder. As the pellets are somewhat denser than the melt, they continue their free fall through the freeboard gas into the melt and continue falling downward in the melt constrained

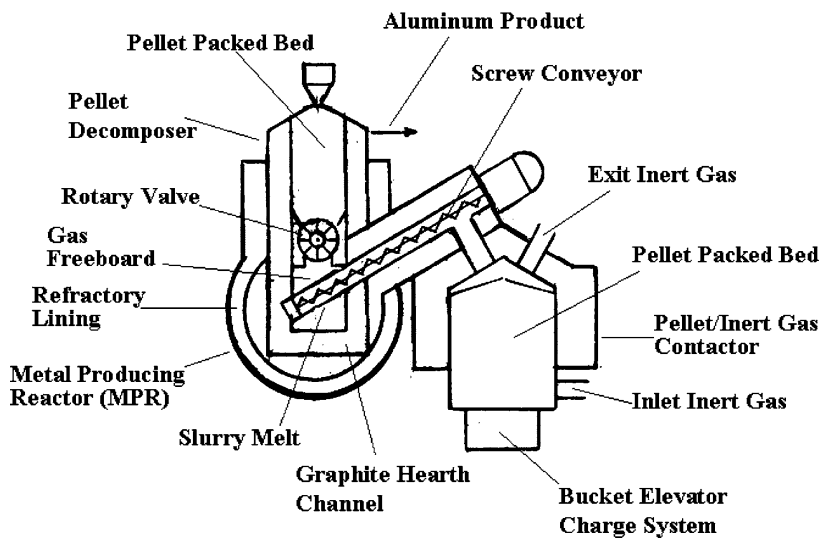

Fig. 8-Sectional end elevation of the pellet decomposer and associated moving packed-bed/inert-gas heat-recovery system, shown in Fig. 6. by a trommel-type screen, constructed of graphite, to enter a screw feeder, also of graphite construction, which elevates the pellets gradually upward, back into the gas freeboard, and then out through the wall of the sump, finally discharging into the top of the moving packed-bed/inert-gas contactor. Heat is recovered from the pellets by countercurrent contacting. The cooled graphite pellets are then recycled back to the top of the decomposer, using the same basic systems as are employed in the analogous nickel carbonyl pellet decomposers of the nickel industry, as referred to previously.

Because the $\mathrm{Al}_{4} \mathrm{C}_{3}$ coating on the graphite pellets is nonresistant to thermal shock, it can be expected to shatter when first entering the melt in the sump, while the graphite pellets themselves should be virtually immune to thermal shock of the magnitude involved. In any event, $\mathrm{Al}_{4} \mathrm{C}_{3}$ rapidly decomposes back to elemental carbon and aluminum at $2160{ }^{\circ} \mathrm{C}$ and any residual $\mathrm{Al}_{4} \mathrm{C}_{3}$ continues to be exposed to high-temperature melt as the pellets proceed upward through the mainstream flowing melt within the screw conveyor, so designed that the melt has ready access to the pellets throughout their passage back to the gas freeboard.

Based on the assumption that at the very high temperatures at which most of the $\mathrm{Al}_{4} \mathrm{C}_{3}$ deposition on pellets occurs, rate control is exclusively liquid-phase diffusion, mass transfer taking place within the pellet decomposer can be assessed using the $j$-factor empirical correlation given by Sherwood et al. ${ }^{[29]}$ in Eq. [22]:

$$
j_{D}=1.17\left(\frac{d_{p} \bar{U}_{A v} \rho}{\mu}\right)^{-0.415}, \quad \text { for } 10<\operatorname{Re}<2500
$$

and

$$
k_{C}=j_{D} \bar{U}_{A v} \mathrm{Sc}^{-2 / 3}
$$

Using Eqs. [22] and [23], it can be shown rigorously that the countercurrent mass transfer taking place in the deposition of $\mathrm{Al}_{4} \mathrm{C}_{3}$ on densified graphite pellets can be achieved in a straightforward fashion. For example, if 3-cm-diameter pellets are employed within a $1.5-\mathrm{m}-$ diameter moving bed packed to a height of $3.5 \mathrm{~m}$, the exit aluminum can be expected to contain no more than $10 \mathrm{ppm}$ C. Similarly, using Reynold's analogy and Eqs. [22] and [23], the required heat transfer by countercurrent contacting of the pellets with recirculated argon, for an approach temperature of $50{ }^{\circ} \mathrm{C}$, can be obtained using a contactor $4.5 \mathrm{~m}$ in diameter packed to a height of $5 \mathrm{~m}$, involving a pressure drop of 0.8 bar. In other words, if the pellets enter at $2160{ }^{\circ} \mathrm{C}$, the argon leaves the top of the packed bed at about $2110{ }^{\circ} \mathrm{C}$. This recirculated argon provides the means for preheating carbon make-up to $2000{ }^{\circ} \mathrm{C}$ via a relatively simple countercurrent contactor involving gas-phase-controlled indirect heat transfer through graphite heat-conducting walls into the fine carbon particles moving along in the reverse direction to the argon flow by means of a graphite screw conveyor. It is envisaged that, if eight impeller-assisted draw down stations are employed, for example, there would be eight graphite countercurrent 
contactors, each delivering its fine carbon charge material via a chute directly into the vortex created by the individual particular impeller.

\section{Off-Gas Quench/Energy Recovery}

For 1 Mtpa Al production, the MPR at 2.8 bar pressure and $2160{ }^{\circ} \mathrm{C}$ has $204.7 \mathrm{~m}^{3} / \mathrm{s}$ gas evolved from the reaction zone, equivalent to a mass rate of $86.1 \mathrm{~kg} / \mathrm{s}$. This off-gas flows through a slot into the gas-quench plenum, a cylindrical pressure vessel mounted downstream from the reaction zone and immediately above the flowing melt surface, in order to avoid direct contact of the hot off-gas with solid walls, as shown in Figure 3. As explained in the process description, the objective is to quench the off-gas by entraining recycled, cooled gas to solidify any aerosol liquid particles, principally $\mathrm{Al}_{2} \mathrm{O}_{3}$, formed when the off-gas is cooled and to give sufficient residence time for them to become nonsticky and thus avoid a serious accretion problem. The Ricou and Spalding ${ }^{[11]}$ analysis for turbulent axisymmetric jets is based on Eq. [24]:

$$
\left(m / m_{o}\right)=0.32\left(x / d_{o}\right)\left(\rho_{l} / \rho_{o}\right)^{1 / 2}
$$

where $m=m_{l}+m_{o}$ and the subscripts $l$ and $o$ refer to the quench-gas and the off-gas mass flowrates, respectively; $x$ is the vertical distance required above the axisymmetric jet source (a slot in the present case) with an equivalent diameter $d_{o}$; and $\rho$ is the gas density. At a 2.8-bar pressure, a quench gas temperature of $125^{\circ} \mathrm{C}$, and a gas off-take temperature of $2160{ }^{\circ} \mathrm{C},\left(\rho_{l} / \rho_{o}\right)=$ 5.63 ; with a quench gas rate of $202.5 \mathrm{~kg} / \mathrm{s}$, the ratio $\left(\mathrm{m} / \mathrm{m}_{o}\right)=3.35$ and, thus, $\left(x / d_{o}\right)$ is 4.41 . For slot jets, it is appropriate to use the equivalent diameter $d_{e}$ (i.e., 4 times the hydraulic radius $r_{h}$ ); therefore, for a slot $1 \mathrm{~m}$ in width $\times 40 \mathrm{~m}$ in length, $r_{h}=0.488 \mathrm{~m}$ and $d_{e}=$ $d_{o}=1.95 \mathrm{~m}$, which gives the height required $(x)$ as $8.60 \mathrm{~m}$. The off-gas velocity through the slot initially is $5.12 \mathrm{~m} / \mathrm{s}$; the Reynolds number $\left(N_{\mathrm{Re}}\right)$ for the slot is $(1.95)(5.12)(0.421) / 74.2 \times 10^{-6}=5.66 \times 10^{4}$. The Ricou and Spalding relationship in Eq. [24] is applicable to $N_{\mathrm{Re}}>2.5 \times 10^{4}$, so the conditions specified fulfill this requirement.

Downstream from the gas-quench plenum, the quenched off-gas proceeds through the well-established plant to recover the thermal energy and preheat the solid feed to the MPR, comprised of Bayer calcined alumina, together with reverted $\mathrm{Al}_{2} \mathrm{O}_{3}$ and $\mathrm{C}$, as obtained on cooling the off-gas. A schematic layout of the energy recovery and preheating arrangements is shown in Figure 2, and the various energy and heat balances from HSC4 printouts are summarized in Table II. With this arrangement, the gas-phase pressure drop is negligible, so the gases emerge at virtually a 2.8-bar pressure, with gas phase equilibria frozen at $1000{ }^{\circ} \mathrm{C}$.

Two alternative approaches for gaseous off take from the MPR are compared in Figure 9: (1) multiple circular jets placed along the length of the MPR or (2) a singleslot jet located downstream from the vigorous MPR reaction zone and, thus, probably requiring a somewhat longer MPR vessel than (1). Both approaches relate to

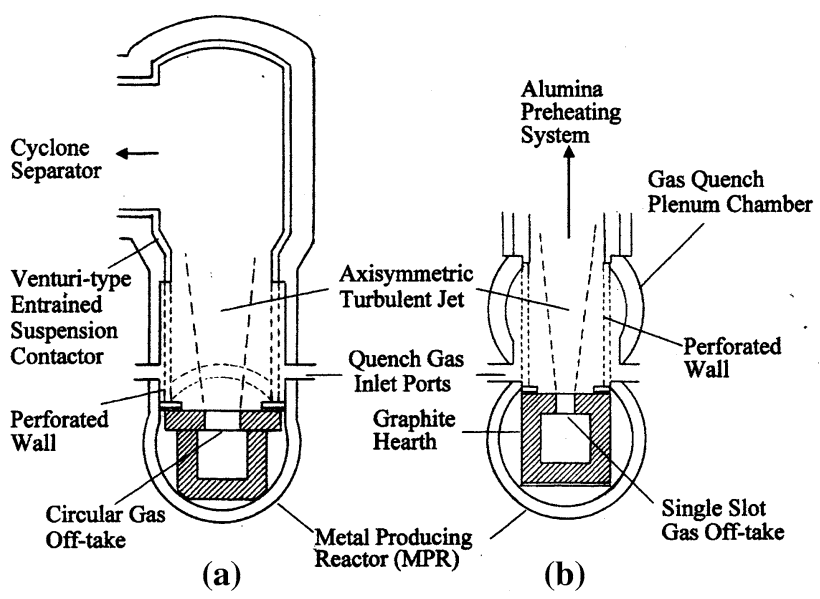

Fig. 9-Comparison in sectional elevation of two alternative approaches for quenching hot gas from the MPR reaction zone.

the production of $1 \mathrm{Mtpa} \mathrm{Al}$; both employ graphite hearth channels $2 \mathrm{~m}$ in width for transporting the slurry melt some $150 \mathrm{~m}$ for (1) and about $190 \mathrm{~m}$ for (2). In both cases, the refractory hearths are enclosed within refractory-lined pressure vessels maintaining an inert gas pressure slightly greater than 2.8 bar, with the total pressure within the MPR nominally 2.8 bar, to prevent the egress of aluminous vapor out into the refractory lining. In both configurations, the off-gas is first quenched by the entrainment of cooled quenched gas via perforated refractory enclosures to which is admitted the quench gas through inlet ports. Cooled quenched gas is recycled from the off-gas stream after sensible heat recovery and charge solids preheating duties, with the remainder proceeding to a shift reactor in advance of gas-turbine-based combined-cycle power generation.

In (1), the off-gas leaves the MPR reaction zone extending over most of the vessel initially as six round jets, each $1.46 \mathrm{~m}$ in diameter with a velocity of $20 \mathrm{~m} / \mathrm{s}$, whereas in (2) a single-slot jet $0.75 \times 40 \mathrm{~m}$ in length discharges the entire off-gas at a velocity of $6.7 \mathrm{~m} / \mathrm{s}$ into a gas-quench plenum. The Reynolds numbers $N_{\mathrm{Re}}$ for each are $>2.5 \times 10^{4}$ and the off-gas is quenched from $2160{ }^{\circ} \mathrm{C}$ to $1955^{\circ} \mathrm{C}$. The entrainment length for each is about the same, because the mean hydraulic radius $\times 4$ of the slot is almost the same as the diameter of the circular jet. For the single-slot jet, discharge takes place into a gas-quench plenum, which is a refractory-lined vessel of similar diameter to the MPR itself and extending for a length of greater than $40 \mathrm{~m}$, so that the expanded jet is accommodated until it is quenched to $1955^{\circ} \mathrm{C}$, after which it flows into a header leading to an alumina preheating system. Clearly, if an entrained Venturi-type contactor coupled to an adjacent cyclone separator is used for both (1) and (2), the volumetric flow in (2) is 6 times larger; thus, for the same gas velocity of $5 \mathrm{~m} / \mathrm{s}$ in the entrainment contactor, for example, the diameter has to be 2.45 times that of the multiple units employed with the round-jet alternative. The multiple units need to be about $5 \mathrm{~m}$ in diameter internally, which means the corresponding single-slot-jet equivalent requires a $12.25-\mathrm{m}$ diameter. In (1), the 
partially heated calcined alumina is admitted into the quench jet at the level corresponding to the location at which its temperature has dropped to $1955^{\circ} \mathrm{C}$ by a downcomer from the preceding cyclone separator, and heat recovery begins immediately. There are many interactions involving complex issues to be resolved in making a firm choice between (1) and (2); thus, for the present purpose, both are viewed as equally acceptable.

\section{E. Pipe Conductive Heaters}

A very significant issue to be solved for the carbothermic production of aluminum, according to Bruno, ${ }^{[1]}$ is how to deliver energy efficiently enough to attain temperatures of $2000{ }^{\circ} \mathrm{C}$ to $2200{ }^{\circ} \mathrm{C}$. In this article, the reaction zone, at $2160^{\circ} \mathrm{C}$, is within this range, but elsewhere within the pipe conductive heaters, it is assumed that a maximum temperature of $2200{ }^{\circ} \mathrm{C}$ can be tolerated. This latter temperature can, of course, be reduced at the expense of an increased melt-circulation rate, as it has already been shown that the meltcirculation energy requirement is of minor significance in comparison to the endothermicity of the chemical reactions involved.

The design now being proposed reflects the sizes of graphite commercially available from UCAR (now Graftech) and the material currently posted on the Internet by the SGL Carbon Group concerning the use of rigid graphite felts for the thermal insulation of hightemperature furnaces. It is noted in particular that Sigratherm RFA rigid felt composite is stable under inert atmospheres up to $3000{ }^{\circ} \mathrm{C}$, but above $2200{ }^{\circ} \mathrm{C}$, its physical properties will change, i.e., the thermal conductivity will increase and the material will shrink. This upper temperature limit of $2200{ }^{\circ} \mathrm{C}$ is, therefore, taken very seriously, and the design offered is, in fact, dominated by this upper temperature limit.

The proposed means for assembling the graphite external pipe heaters for conductively heating the circulating melt slurry is shown in Figure 10. This employs a series connection of individual graphite modules, which are joined together, one after the other, to form a conduit for the circulation of the melt external to the MPR. The technology developed for the construction of columns of large graphite electrodes (up to $800 \mathrm{~mm}$ in diameter $\times 2800 \mathrm{~mm}$ in length) for electric arc furnaces, which are assembled into columns (usually three to a column), can be adapted to joining the individual modules to each other, analogous to the tapered sockets and double-tapered machine-threaded nipple arrangement used in electrode column assembly. Although a relatively small fraction of the total electric current flows through the graphite wall of the module, in comparison to the major current flow in the melt slurry, which is mainly within the so-called "penetration depth" associated with alternating current (AC), it is still important for the stability of the operation that the electrical circuit integrity is preserved by appropriate graphite-jointing techniques.

Notwithstanding electric current aspects, the overriding concern is to ensure that the joints are leakproof. For this, the adaptation of the joint sealing methods and

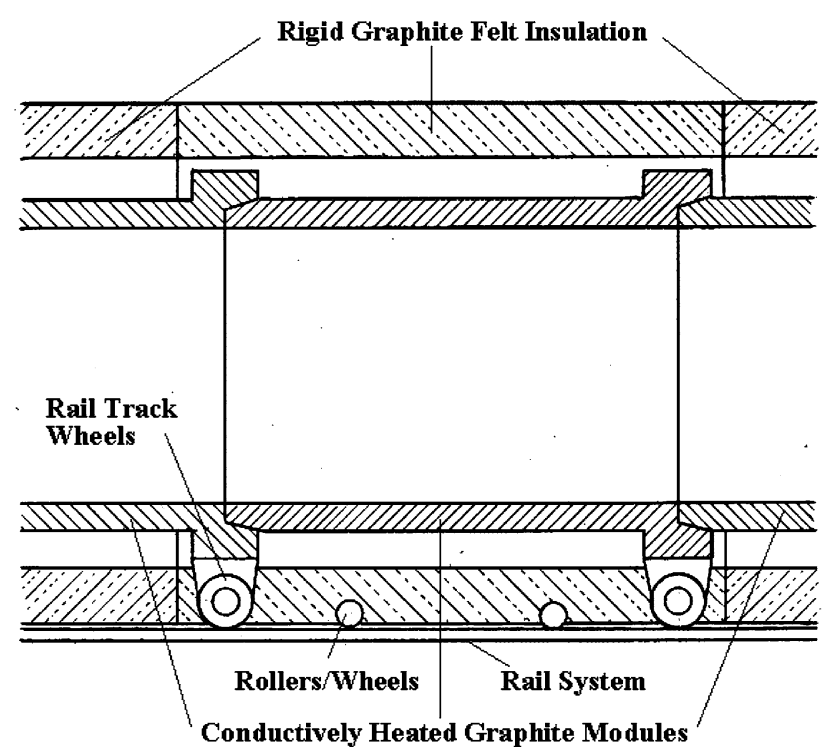

Fig. 10-Basic design in cross-sectional elevation of one of the modular units used in graphite pipe heaters.

materials currently used in aluminum electrolytic cells is clearly the basis for the preferred approach. Hollow cylinders of rigid graphite felt thermally insulate the conductively heated modules, but careful design is essential, so that the rigid felt composite made from graphite fibers and a carbon binder does not have electrical contact with the heater modules. For pipe heaters, which may be well in excess of $200 \mathrm{~m}$ in length, differential thermal expansion must be addressed from the outset. An arrangement of rail-track wheels is provided, to permit lateral movement along the straight length of the heater, which is transmitted to the metal pool/snorkel configuration to be introduced in Figure 11. The rigid graphite felt hollow cylinders are also provided with rollers or wheels or, alternatively, are skid mounted to simplify construction. The rail system clearly has to be supported on a secure refractory foundation, which is contiguous with the insulating firebrick, or perhaps with monolithic refractory material, which lines the containment vessel, running the length of the assembled pipe heater. This maintains the protective inert gas atmosphere at a predetermined pressure, normally close to atmospheric pressure. All components shown in Figure 10 are of graphite or carbon-fiber reinforced-graphite construction, except perhaps the rails, which, subject to experimental evaluation, may be fabricated from ceramic material.

The components shown in Figure 10 are all installed asymmetrically within a refractory-lined shell, to permit access by personnel for inspection and maintenance along the full length of the pipe heaters. There are two external melt-circulation loops, one on each side of the main melt-circulation production line of a pressurized MPR and pellet decomposer sump operating at pressures of 2.8 bar, and then a sequence of downstream processing units, as well as the pipe-conductive heaters themselves, all at essentially atmospheric pressure, for example, at 1.3 bar. These downstream components are 

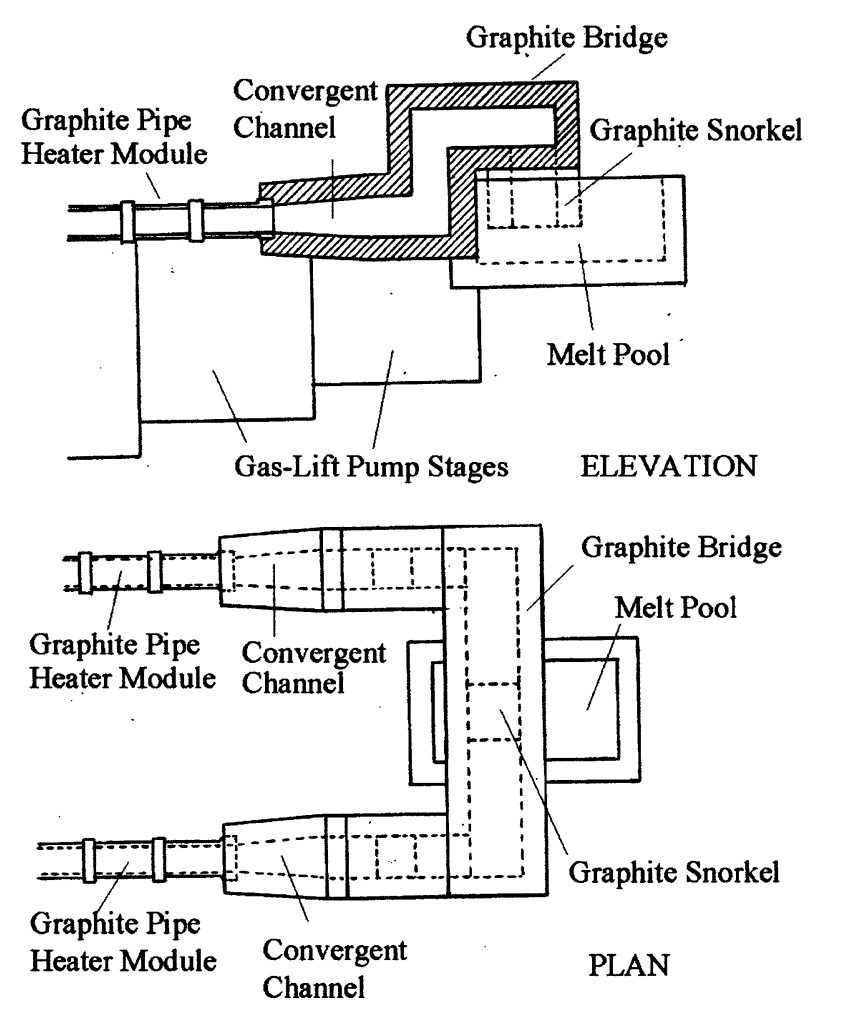

Fig. 11-Graphite snorkel and melt-pool arrangement for accommodating differential thermal expansion between pipe heaters and central MPR processing units.

attached to the higher-pressure region via barometric legs.

The two melt-circulation loops each share a common flow path of MPR, etc., which means that a single gaslift pump arrangement services both loops in parallel. The electrical circuit is somewhat different. Under normal steady-state operation, there is no current flow through the MPR melt flow path. With the heavy current input located at the center of both external straight-line arms, each about $226 \mathrm{~m}$ in length, in effect, the conductive heating takes place in four identical resistors or four so-called "pipe heaters," each contributing one quarter of the electrical load to satisfy the endothermicity of the $\mathrm{Al}_{2} \mathrm{O}_{3}$ reduction to $\mathrm{Al}$. The MPR line is at earth potential during normal operation, and it is only during temporary shutdowns that independent low voltage/heavy current systems are applied locally within the circuit, to maintain the contained melt above $2150{ }^{\circ} \mathrm{C}$, to prevent $\mathrm{Al}_{4} \mathrm{C}_{3}$ formation.

For electric circuit calculations, each pipe heater is $113 \mathrm{~m}$ in length, with an inside diameter of $1 \mathrm{~m}$. The total thermal load in the MPR for the proposed operating conditions is detailed in the HSC4 equilibrium calculations shown in Table I. For the production of 2mol Al, the reaction enthalpy is shown to be $2124 \mathrm{~kJ}$, assuming 100 pet recovery. For $1 \mathrm{Mtpa} \mathrm{Al}$ (i.e., $1.174 \mathrm{kmol} / \mathrm{s})$, an electrical power input of $2171 \times 1.174 / 2.0=1246.8 \mathrm{MW}$, in the absence of any heat losses. Accordingly, the minimum power input required per pipe heater is $311.7 \mathrm{MW}$.
If the "melt" (i.e., carbon-saturated aluminum plus 10 vol pet $\langle C\rangle$ ) flows through each loop in parallel at rates of $3.71 \mathrm{~m}^{3} / \mathrm{s}$, which reflects the heat balance on the MPR given in Table I, with the entrance at $2200{ }^{\circ} \mathrm{C}$ and the exit at $2160{ }^{\circ} \mathrm{C}$ for $1 \mathrm{Mtpa} \mathrm{Al}$, then $N_{\mathrm{Re}}=2.17 \times$ $10^{7}$ and the friction loss is about $4.7 \mathrm{~m}$ for a $225-\mathrm{m}$ straight length. The effective resistance for a $50-\mathrm{Hz} \mathrm{AC}$ current flow in parallel through the melt and graphite wall is estimated for each pipe heater (i.e., $113 \mathrm{~m}$ of pipe) to be $4.02 \times 10^{-4} \Omega$. Since the estimated power input required per pipe heater is about $312 \mathrm{MW}$, the amperage required is nominally about $881 \mathrm{kA}$.

Thermal expansion must be taken into account for pipe loops installed initially at ambient temperature and then experiencing temperatures up to $2200{ }^{\circ} \mathrm{C}$ in steadystate operation. It is suggested that overall and differential changes in length may be accommodated using sumps containing the melt into which there are immersed pipe inlets or "snorkels" with the freedom to move in all directions, with adequate clearance of melt around them. The system illustrated in Figure 11 permits the differential thermal expansion in excess of $2 \mathrm{~m}$ to be accommodated by movement in a melt pool just after the gas-lift pumping arrangement. The floating end for expansion provision is rather like a conventional siphon, requiring a reduced pressure to be applied to initiate flow to or from the pool of liquid metal. The graphite pipe modules, which make up the flow conduits of the external pipe heaters, are joined to a graphite bridge, with the cross-sectional area for flow being gradually increased by a divergent channel (included an angle $<7 \mathrm{deg}$ ), in advance of three right-angled bends that permit a graphite snorkel to be immersed in a pool of the melt slurry. The arrangement shown is necessary in order to avoid unacceptably large head losses incurred for fluid flow through 90-deg short elbows. An arrangement similar to that shown in Figure 11 can be provided at both ends of the straight-line pipe heaters, where the flow through the assembled modules joins the mainstream common flow circuit of the MPR and ancillaries. The movement of snorkels in the melt pools takes up thermal expansion in the long, straight pipe heaters. The arrangement shown in Figure 11 is connected to the melt discharged from the gas-lift pumping system shown in Figure 5. The final pumping stage discharges melt directly into the liquid pool. At the other end of the pipe heater, where the melt returns to the MPR, a barometric leg (not shown) from the pressurized MPR is connected to an analogous snorkel/ melt pool system, again to take up thermal movement of the straight-line pipe heaters, one on each side of the MPR. With this arrangement, the centers of the straight-line pipe heaters are in fixed positions for electrical current introduction via hubs (not shown).

\section{F. Heavy Current Distribution}

Current distribution is based solely on an aluminum bus system with molten pure aluminum at one end of the current distribution launders at, for example, $700{ }^{\circ} \mathrm{C}$, and by controlled heat removal to generate process steam, and with solid aluminum at the other end, cooled 
to around $300{ }^{\circ} \mathrm{C}$. Conventional aluminum busbars are welded directly to the solidified $\mathrm{Al}$ in the launders and, thus, virtually eliminate contact resistance altogether.

To prevent the passage of carbon-saturated melt by convection and to counter the molecular diffusion of carbon back into the hub and the subsequent accumulation of precipitated $\mathrm{Al}_{4} \mathrm{C}_{3}$ in the cooler regions, leading to blockage and the serious restriction of current flow, a very small flow of aluminum must be established in the reverse direction. This can be achieved by melting scrap in the hub or, alternatively, by using existing electromagnetic or submerged centrifugal pump technology to return a small "reflux" of the molten aluminum product to the hub. In both cases, to protect the graphite lining of the very short launder connecting the hub to the principal melt circulation, it will be necessary to incorporate some fine carbon particles into the melt using a single impeller draw down. This is not to be seen as extra carbon consumption, but rather the diversion of a small fraction of the make-up carbon away from the principal addition region.

\section{G. Saltation Velocity of Carbon Particles}

For the horizontal transport of dispersed solids, the minimum fluid velocity for keeping all solid particles in suspension is referred to as the saltation velocity. If the melt-circulation velocity is reduced to the saltation velocity, the largest particles begin either to settle or to float out of the dispersed state. To a first approximation, the carbon particles can be expected to have a density of about $2150 \mathrm{~kg} / \mathrm{m}^{3}$, whereas the density of carbonsaturated aluminum at $2160{ }^{\circ} \mathrm{C}$ is estimated to be $1978 \mathrm{~kg} / \mathrm{m}^{3}$, in which case carbon particles will begin to sink to the bottom of a melt flowing in an open channel, such as the MPR, once the velocity is reduced below the saltation velocity.

The appropriated saltation velocity was evaluated using the empirical procedures outlined by Kunii and Levenspiel. ${ }^{[30]}$ With the MPR at a mean temperature of $2160{ }^{\circ} \mathrm{C}$ for spherical particles $50 \mu \mathrm{m}$ in diameter, the critical saltation velocity in a $6.35-\mathrm{cm}$-diameter pipe is a value of $0.0286 \mathrm{~m} / \mathrm{s}$, which corresponds to a velocity of $0.161 \mathrm{~m} / \mathrm{s}$ for a channel with an equivalent hydraulic diameter of $4.8 \mathrm{~m}$. This is based on the relationship given by Kunii and Levenspiel, ${ }^{[30]}$ in which the critical velocity is proportional to (diameter) ${ }^{0.4}$. It is assumed that the equivalent diameter (i.e., $4 r_{h}$ ) is applicable and that the dispersion of inert fine solid particles of carbon in carbon-saturated aluminum does not affect the Newtonian flow and physical properties of the melt. Furthermore, in the absence of a known particlesize distribution, only single-particle behavior was considered.

In the event of concern about the large particles dominating the particle-size distribution of the dispersed carbon particles, some location in the overall circuit would need to be designed such that the cross-sectional area of the melt channel is increased, to reduce the velocity down to the saltation velocity for carbon particles $50 \mu \mathrm{m}$ in diameter, for example, and then sufficient residence time provided at the lower velocity to permit the required number of the largest particles to settle out, to form a bottom layer or sludge. The sludge would be continuously thickened, possibly with mechanical assistance. An appropriate amount of solids in the sediment bed of the coarser particles would be withdrawn, in association with a predetermined amount of aluminum melt, probably corresponding to the product aluminum make. External milling of the larger carbon particles would be necessary in this scenario, before the equivalent mass of carbon in slurry form is returned to the melt circuit.

None of the actions in the preceding paragraph needs to be implemented, if, in fact, the actual or mathematically modeled particle-size distribution remains adequate for the protection of graphite surfaces. A decision on this, therefore, has to be deferred at this stage.

\section{H. In-plant Power Generation}

Let us now consider the recovery of energy from the byproduct $\mathrm{CO}$ in the cooled off-take gas from the MPR. It is customary in gasification and similar studies to assume that gas phase equilibria involving $\mathrm{CO}$ and $\mathrm{CO}_{2}$ are frozen by the time gases are cooled to $1000{ }^{\circ} \mathrm{C}$; therefore, the same basis has been used here. In theory, the cooled gas contains 98.1 vol pet $\mathrm{CO}$ and 1.9 vol pet $\mathrm{CO}_{2}$ and, at first sight, may appear a premium fuel for combined-cycle gas-turbine (CCGT) power generation. The lower heating value (LHV) of $\mathrm{CO}$ is $283 \mathrm{~kJ} / \mathrm{mol}$ compared with the LHV of hydrogen at $242 \mathrm{~kJ} / \mathrm{mol}$. However, combustion of $\mathrm{CO}$ is far from straightforward and is limited by serious kinetic constraints, which preclude comparison with $\mathrm{H}_{2}$ and even dismiss altogether pure $\mathrm{CO}$ as a gas-turbine fuel unless it is mixed with $\mathrm{H}_{2}$.

On the other hand, many experts are continuing to predict that fuel cells will find widespread use in the conversion of chemical to electrical energy, as they offer very high efficiencies. The solid oxide fuel cell (SOFC) is the most relevant; notable in the present context is its ability to use essentially pure $\mathrm{CO}$ as a fuel ${ }^{[31]}$ and to directly produce $\mathrm{CO}_{2}$ ready for immediate disposal without incurring the cost of a conventional oxygen plant. ${ }^{[32]}$ However, further consideration of emerging SOFC technology relevant to carbothermic aluminum smelting is not pursued, because the impression must not be given that the proposed aluminum process is reliant on future SOFC developments. Therefore, a conventional approach to advanced power generation using well-established technology has been used to evaluate the in-house power generation for assessment of the total energy requirements.

From what has already been said, it is obvious that the process off-gas comprised principally of carbon monoxide has to be modified to incorporate $\mathrm{H}_{2} / \mathrm{H}_{2} \mathrm{O}$ or, in other words, shift-reaction chemistry has to be introduced into the flowsheet by equilibrating $\mathrm{CO}$ with superheated steam in a shift reactor, using a standard shift catalyst for this purpose. Advanced double-reheat steam-turbine power generation with steam conditions 320 bar $/ 620{ }^{\circ} \mathrm{C} / 620^{\circ} \mathrm{C} / 620{ }^{\circ} \mathrm{C}$ was selected, because high-chrome ferritic steels are superior on a cost basis 


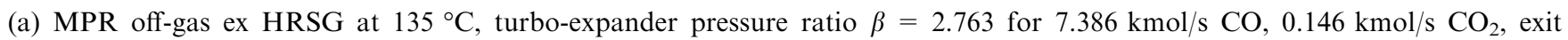
temperature $35^{\circ} \mathrm{C}$; gross shaft power $=22.92 \mathrm{MW}$.

(b) Recycle quench gas for MPR: $5.594 \mathrm{kmol} / \mathrm{s} \mathrm{CO}, 0.111 \mathrm{kmol} / \mathrm{s} \mathrm{CO} 2$ cooled to $20{ }^{\circ} \mathrm{C}$ at 1 atm, compressed to 2.8 bar, consuming 17.88 MW, available for quenching at $125^{\circ} \mathrm{C}$.

(c) Fuel gas for shift reactor: $1.792 \mathrm{kmol} / \mathrm{s} \mathrm{CO}, 0.0352 \mathrm{kmol} / \mathrm{s} \mathrm{CO}_{2}$ compressed to 10 bar with $\beta=9.869$, consuming $16.03 \mathrm{MW}$ and exiting at $328^{\circ} \mathrm{C}$.

(d) Fuel gas preheated from $328{ }^{\circ} \mathrm{C}$ to $780{ }^{\circ} \mathrm{C}$; heat input required $26.84 \mathrm{MW}$.

(e) Catalytic shift reactor at $800{ }^{\circ} \mathrm{C}$ : steam addition $0.587 \mathrm{kmol} / \mathrm{s}$ at $190{ }^{\circ} \mathrm{C}$, saturated 12.5 bar, producing: $1.351 \mathrm{kmol} / \mathrm{s} \mathrm{CO}$, $0.476 \mathrm{kmol} / \mathrm{s} \mathrm{CO}_{2}, 0.441 \mathrm{kmol} / \mathrm{s} \mathrm{H}_{2}$, and $0.146 \mathrm{kmol} / \mathrm{s} \mathrm{H}_{2} \mathrm{O}$ at $10 \mathrm{bar}$.

(f) Gas turbine: combustor at $10 \mathrm{bar} / 1350{ }^{\circ} \mathrm{C}$ with $\beta=9.869$ producing shaft work $=283.6 \mathrm{MW}$.

(g) Shaft balance: work input 283.6 MW less (air compression 107.22 MW, fuel gas compression 16.06 MW), gives gross power available $=160.39 \mathrm{MW}$ and net electric power $=155.11 \mathrm{MW}$.

(h) Supercritical steam generated: MPR quenched gas $\mathrm{HRSG}=50.5 \mathrm{~kg} / \mathrm{s}$, HRSG after gas turbine $=86.8 \mathrm{~kg} / \mathrm{s}, \mathrm{MPR}$ heatrecovery circuit (used principally for reheat 1 plus reheat 2) $=22.4 \mathrm{~kg} / \mathrm{s}$. Total supercritical steam $=159.7 \mathrm{~kg} / \mathrm{s}$.

(i) Steam turbine:

Supercritical steam heat input

Reheat $1+$ reheat 2

557.3 MW

167.2 MW

Enthalpy steam to condenser

Enthalpy recovered to shaft work

$368.8 \mathrm{MW}$

Gross electric power generated

355.6 MW

Less

(feedwater pump 7.69 MW

transformer loss $1.42 \mathrm{MW}$ )

Net electric power generated

$349.2 \mathrm{MW}$

(j) Overall total in-plant electric power generation:
(i) Steam turbine
(ii) Gas turbine
(iii) Turbo-expander
Total in-plant power generated
$=340.1$
$=155.1$
$=21.7$
$=\frac{21.7}{516.9} \mathrm{MW}$

340.1 MW

to austenitic stainless steels, and the conditions chosen are approaching the current upper limit for ferritic steels. The design calculations were based on the component performance factors and reference plant conditions listed by Bannister et al. ${ }^{[33]}$ in their final report on hydrogen-fueled combustion-turbine power generation. These authors assumed HRSG operation at atmospheric pressure producing supercritical steam, $93 \mathrm{pct}$ isentropic efficiency with $99.2 \mathrm{pct}$ generator efficiency for turbomachinery with 0.6 pct bearing losses (percent of shaft power), pumps with 85 pct adiabatic efficiency, and 98 pct electric motor efficiency. Some of the key parameters are given in Table IV for the production of 1 Mtpa Al.

\section{DISCUSSION}

It has been perceived that one very important incentive for pursuing carbothermic reduction is the ability to produce aluminum on a small scale cost effectively. ${ }^{[34]}$ However, this would not appear to be the way forward, if legitimate concerns are accepted with regard to global climate change. Whatever the primary aluminum process, carbon emissions are inevitable, so carbon capture and storage (CCS) must be considered in forward planning. It is inconceivable that CCS can be undertaken cost effectively on a small scale. Economies of scale are vital for the future of the primary aluminum industry; hence, the focus in this article has been on a nominal production of $1 \mathrm{Mtpa} \mathrm{Al}$ with an implied total of $3 \mathrm{Mtpa} \mathrm{Al}$, if electric power phase balancing is an issue. Production facilities based on electric furnace technology using graphite electrodes and mini mills are clearly viable for secondary aluminum, but climate change and global warming probably negates such an approach for the primary industry.

Throughout the conceptual design, it has been assumed that the creep of graphite structural components is not an overwhelming issue at the selected operating temperatures. The proposed maximum has been set at $2200{ }^{\circ} \mathrm{C}$, which is reached just before the circulating melt discharges from the external graphitelined pipe heaters immediately prior to entry into the backmixed MPR reactor, where the temperature drops effectively to $2160{ }^{\circ} \mathrm{C}$ throughout. The temperature then falls to around $2158{ }^{\circ} \mathrm{C}$ within the gas-lift multistage pumping system before being readmitted to the external graphite pipe heaters. By increasing the melt-circulation rate, the $2200{ }^{\circ} \mathrm{C}$ figure can be reduced at the expense of increased energy consumption. For example, increasing the melt flow by a factor of 2 would drop the maximum temperature to $2180{ }^{\circ} \mathrm{C}$ while maintaining the MPR temperature at $2160{ }^{\circ} \mathrm{C}$.

The practicality of the conceptual design depends critically on the ability to physically contain the melt at the very high temperatures involved without mechanical failure or leakage. Thermal expansion issues must also be addressed from the outset. Perhaps in certain areas, it may be necessary to accept a degree of leakage with graphite runoff channels provided in association with barometric legs, to return the melt to strategically located atmospheric sumps at essentially atmospheric pressure with protective atmosphere provision. 
These runoff channels would need to be independently conductively heated to ensure essentially isothermal operation, in order to prevent solids deposition and subsequent blockage.

In comparing the total energy requirements for various processes, Kellogg ${ }^{[35]}$ introduced the concept of the process fuel equivalent (PFE). With the availability of nuclear, hydro, or geothermal power, the evaluation of PFE is simply the addition of electrical input plus the LHV of the fuel used directly in the process. If, however, fuel is combusted to generate electricity, the inherent cycle thermodynamic limitations must be taken into account; this requires assessment of the net energy conversion efficiency as well as transmission losses, if combustion occurs in a power station some distance from the metallurgical process.

According to Welch, ${ }^{[2]}$ in the 1980 s, a number of articles were published on the Hall-Heroult process, claiming achieved energy-consumption figures less than $12.5 \mathrm{kWh} / \mathrm{kg} \mathrm{Al}$; since then, however, the emphasis has been on a shift to high-amperage technologies that are less energy efficient but more cost effective. For example, $400 \mathrm{kA}$ cells were introduced in Russia in January, 2006, with current efficiency expected to exceed 94 pct and power consumption less than $13.8 \mathrm{kWh} / \mathrm{kg} \mathrm{Al}$.

The expansion of the traditional Hall-Heroult process, stemming from the diversification away from oil resources in certain Gulf countries in favor of the greater use of natural gas for aluminum production, in particular, has surged and is ongoing. For example, aluminum production at a single site has reached $840,000 \mathrm{tpa}$, using the world's longest potline $(1.2 \mathrm{~km}$ in length), employing some 336 cells. Also, in April, 2007, it was announced that an integrated "mine-tometal" aluminum project, including bauxite mining, alumina refining, power generation, and aluminum smelting, was being planned for the region. The ultimate scale of this project is stated to be $2 \mathrm{Mtpa}$ Al. Assuming that electricity is generated by state-of-theart $1500{ }^{\circ} \mathrm{C}$-Class gas turbines with a net efficiency of $60 \mathrm{pct}$, the electrolysis energy consumption is $13.8 \mathrm{kWh}$ per $\mathrm{kg}$ aluminum, and the overall carbon consumption is $453 \mathrm{~kg}$ per ton aluminum, as derived from figures given by Bruno, ${ }^{[1]}$ the PFE for these projected Hall-Heroult potlines in going from refined Bayer alumina to aluminum metal is $97.65 \mathrm{MJ}$ per $\mathrm{kg} \mathrm{Al}$. However, the availability of nuclear, hydro, or geothermal power for the Hall-Heroult process offers lower energy consumption for processing Bayer alumina to primary aluminum metal with a minimum PFE value of $64.53 \mathrm{MJ} / \mathrm{kg} \mathrm{Al}$, using the same electricity and carbon consumption as described here, but excluding any ancillary power requirements.

At the present time, Russia has the two largest hydroelectric-based plants with annual outputs in 2006 of 984,000 and 948,000 tons of primary aluminum. In October 2007, it was announced that the world's biggest aluminum smelter with a capacity of 1.05 million tons per year may be built in Russia's Saratov region, complete with two nuclear reactors for the power required.

In the longer term, to combat global warming, a hydrogen economy may be deemed necessary, in which hydrogen is used for transport and other purposes requiring mobility, while large stationary industrial plants continue to use fossil and biomass fuel in association with carbon dioxide CCS. Some experts foresee that decarbonization of natural gas as the best way forward for the production of hydrogen, in which case elemental carbon (carbon black) would become available at prices competitive with other sources of energy. Under these conditions, the carbothermic production of aluminum would have clear advantages over other technologies. The CCS would probably be mandatory in this scenario and economies of scale would be needed to offset the additional costs involved.

At first sight, because of concerns about climate change and global warming, it may seem inappropriate to be promoting carbon-based technology at the present time. But a more detailed appraisal in light of the rapidly advancing progress in carbon dioxide CCS worldwide, together with a possible move toward a hydrogen economy in the longer term, highlights the benefits of the newly proposed aluminum technology and puts the matter in a somewhat different perspective. The over-riding factors in the longer term are sustainability and economic viability. Clearly, carbon can be biomass based and, thus, carbon neutral. Also, accelerating developments in solar-energy-based methane (natural gas) thermal decomposition to produce hydrogen and elemental carbon (carbon black) as a byproduct could have a substantial beneficial effect on the primary aluminum industry.

There is, of course, a trade-off between electricity and carbon as the energy source used, but if low-cost carbon is available, savings in electricity consumption must be of paramount importance. The new technology outlined in this article requires an input of electricity from external sources of $6.72 \mathrm{kWh} / \mathrm{kg}$ Al. In comparison with the $13.8 \mathrm{kWh} / \mathrm{kg} \mathrm{Al}$ for the $400 \mathrm{kA}$ cell technology, this represents a saving of 51.3 pct.

The electrolytic route still has to contend with greenhouse gas emissions and, because of the nature of the Hall-Heroult process, the CCS for this is not going to be straightforward. In contrast, the higher-temperature carbothermic route initially produces $\mathrm{CO}$, as opposed to $\mathrm{CO}_{2}$ in Hall-Heroult. The total carbon consumption for Hall-Heroult is in the region of $0.45 \mathrm{~kg} / \mathrm{kg} \mathrm{Al}$, whereas the new carbon input for the carbothermic route under discussion is about $0.67 \mathrm{~kg} / \mathrm{kg}$ Al. However, this increased carbon input is more than compensated for by the fact that the CCS for the new technology is expected to be considerably more straightforward. In particular, having liquid $\mathrm{CO}_{2}$ ready for immediate disposal underground is potentially within reach without a major energy penalty, when starting from virtually pure $\mathrm{CO}$, as promised by the SOFC technology ${ }^{[31]}$ now in an advanced stage of development.

Hall-Heroult has environmental problems arising from the anode effect in relation to formation of perfluorocarbons, as pointed out by Bruno. ${ }^{[1]}$ The estimated greenhouse equivalent $\mathrm{CO}_{2}$ emission due to this phenomenon is $2.20 \mathrm{~kg} \mathrm{CO}_{2} / \mathrm{kg} \mathrm{Al} .^{[1]}$ This brings an equivalent carbon emission of $0.6 \mathrm{~kg} \mathrm{C}$, making the total $1.05 \mathrm{~kg} \mathrm{C} / \mathrm{kg} \mathrm{Al}$, which is then larger than the 
estimated value of $0.67 \mathrm{~kg} \mathrm{C} / \mathrm{kg}$ Al for the proposed carbothermic process.

\section{CONCLUSIONS}

The new approach is focused on an aluminum MPR system, in which aluminum oxide reacts directly with molten carbon-saturated aluminum under highly intensive dispersed-contact conditions such that aluminum carbide $\left(\mathrm{Al}_{4} \mathrm{C}_{3}\right)$ is thermodynamically unstable as an intermediate. The oxide and dissolved carbon in the liquid aluminum react directly together to produce aluminum metal and carbon monoxide gas at temperatures typically in the region of $2160{ }^{\circ} \mathrm{C}$ at $2.8 \mathrm{bar}$ absolute pressure. For closed-loop melt circulation, provided the temperature and pressure is selected so that melts of $\mathrm{Al}_{4} \mathrm{C}_{3} / \mathrm{Al}_{2} \mathrm{O}_{3}$ cannot form, carbon or graphite structures can be used indefinitely with an appropriate protective melt-circulation medium. Stable slurries of fine carbon particles dispersed in carbonsaturated aluminum fulfill this essential requirement.

There are no major difficulties in feeding fine carbon into the melt and for particles 20 to $30 \mu \mathrm{m}$ or so in diameter. Nonwetting is not an issue for particles of this size. Impeller-assisted incorporation of fine carbon particles into the circulating melt requires very little energy input in comparison to the endothermicity of the smelting reduction reaction itself. If differential expansion is adequately provided for and the maximum temperature is no more than $2200{ }^{\circ} \mathrm{C}$, melt circulation in two closed loops of graphite pipe $1 \mathrm{~m}$ in diameter does not present any identifiable demanding practical problems. The pipes need to be fully supported, but with complete freedom to expand longitudinally. The friction head of less than $5 \mathrm{~m}$ can be overcome readily by four in-line stages of simple gas-lift pumping, again with minimal energy input.

Except in the pellet decomposer, where the aluminum product melt is cooled, the whole circuit must be maintained above $2150{ }^{\circ} \mathrm{C}$ to $2160{ }^{\circ} \mathrm{C}$, to prevent $\mathrm{Al}_{4} \mathrm{C}_{3}$ formation; issues related to the formation of $\mathrm{Al}_{4} \mathrm{C}_{3}$ elsewhere are theoretically irrelevant. The nickel industry has reliable pellet decomposers in which nickel carbonyl in the fluid phase is decomposed to nickel on recirculated nickel pellets acting as heat transfer media. By analogy, $\mathrm{Al}_{4} \mathrm{C}_{3}$ deposition on recirculated carbon or graphite spherical pellets acting as heat-transfer media under transport-controlled conditions can be rigorously quantified and shown to be a viable solution to the carbide problem normally associated with carbothermic aluminum production as well as potentially delivering a final aluminum product with an extremely low carbon content and significant energy savings.

Carbothermic reduction under a modest pressure of 2.8 bar absolute is sufficient to contain chemical energy losses associated with evolution of $\mathrm{Al}_{2} \mathrm{O}_{(g)}$ and $\mathrm{Al}_{(g)}$ to acceptable proportions. Pressurization to 2.8 bar is limited to the principal metal-producing chemical reactor and its associated gas-quench system, but elsewhere, the incorporation of barometric legs in the flow circuit permits the system to be operated at essentially atmospheric pressure. To provide the driving force for the inert gas movement and the simplification of energy recovery aspects, an absolute pressure of 1.3 bar has been chosen, rather than atmospheric pressure.

There is no suggestion that the melt can be contained anywhere with a frozen ledge. The energy losses would be enormous. The whole melt-circulation circuit is saturated with carbon throughout, so graphite containment is the obvious solution. Very detailed consideration has been given to the strategy of using a slurry of dispersed carbon particles in carbon-saturated aluminum, to protect graphite surfaces from dissolution. No theoretical or practical impediment has been discovered. A $10 \mathrm{vol}$ pct dispersion of fine carbon particles is put forward initially, but this clearly requires optimization. Saltation effects cannot be disregarded just because the flow is turbulent, so due regard is given to this phenomenon, to ensure stability throughout the almost horizontal melt-circulation loops.

The use of elemental carbon as the reductant in association with electrical conductive heating, based on the availability of nuclear, hydro, or geothermal power, yields a PFE of $48.22 \mathrm{MJ} / \mathrm{kg} \mathrm{Al}$ for a MPR at $2.8 \mathrm{bar}$ and $2160{ }^{\circ} \mathrm{C}$, as detailed in Table V. This PFE is not burdened with the various energy-consumption terms associated with forming and baking anodes, cathode replacement, chemicals (electrolyte), and environmental control, which collectively add an estimated $3.15 \mathrm{MJ} / \mathrm{kg}$ Al to the figure of $64.53 \mathrm{MJ} / \mathrm{kg} \mathrm{Al}$ already identified,

Table V. Assessment of PFE (MJ/kg Al)

(a) Thermal demands on melt circulation

(i) Endothermicity of MPR reaction 37.91 zone (Table I)

(ii) $\mathrm{Al}_{4} \mathrm{C}_{3}$ coated pellets assimilation 1.20 in melt

(iii) Fine carbon particles increased to 0.22 melt temperature

(iv) Gas-lift pumping: $\mathrm{Al}_{(g)}$ and $\operatorname{Ar}_{(g)} \quad 0.14$ thermal requirements

(v) Current introduction via hub 0.11 connectors

(b) Electrical powered ancillaries

(i) Argon heat-recovery circuit booster

(ii) $\mathrm{Ar}_{(g)}$ gas-lift booster

(iii) Recycle gas-quench booster

(iv) Candle filters $\operatorname{Ar}_{(g)}$ compressor

(v) Carbon particle drawdown

(vi) Pellet bucket elevator/screw conveyor

Total electrical power requirement Minus in-house power generation Net electrical power consumption $(\mathrm{PFE})_{\text {Electrical }}$

39.58

0.33

$9.9 \times 10^{-3}$

0.56

0.01

$9.8 \times 10^{-3}$

$0.2 \times 10^{-3}$

0.92

40.50

16.31

$\frac{16.31}{24.19}$

$=24.19$

(c) Carbon reductant (stoichiometric) $3 \mathrm{~mol} \mathrm{C}$ per $1 \mathrm{~mol} \mathrm{Al}_{2} \mathrm{O}_{3}$ consumed $(\mathrm{PFE})_{\text {Carbon }}$

$=21.86$

(d) Additional fossil fuel requirement

$(\mathrm{PFE})_{\text {Fuel }}$

$(\mathrm{PFE})_{\text {Total }}$

$=2.17$

$=48.22 \mathrm{MJ} / \mathrm{kg} \mathrm{Al}$ 
making the total Hall-Heroult process $67.68 \mathrm{MJ} / \mathrm{kg} \mathrm{Al}$ for $1380 \mathrm{kWh} / \mathrm{kg}$ cells. On these grounds, it would appear that there are potential overall energy savings in the proposed technology of 28.75 pct, in comparison to the higher-amperage, cost-effective potlines currently in vogue.

\section{REFERENCES}

1. M.J. Bruno: Proc. Technical Sessions, presented by the TMS Aluminum Committee, 132nd TMS Annual Meeting, TMS, Warrendale, PA, 2003, pp. 395-400.

2. B.J. Welch: JOM, 1999, vol. 51 (5), pp. 24-48.

3. J.G. Peacey and W.G. Davenport: The Iron Blast Furnace Theory and Practice, Pergamon Press Ltd., New York, NY, 1979, Table 1.1 , pp. 4-5.

4. C. Qiu and R. Metselaar: J. Alloys Compd., 1994, vol. 216, pp. 55-60

5. L.L. Olden and R.A. McClune: Metall. Trans. A, 1987, vol. 18A, p. 2005.

6. A. Roine: HSC Chemistry 4.0, Outokumpu Research Oy, Finland, June 1999.

7. N.A. Warner: Co-Production of Steel, Titanium and High Grade Oxide, International Patent Application WO 2007/122366 A1, Nov. 2007.

8. N. El-Kaddah and K.E. Chang: Mater. Sci. Eng., 1991, vol. A144, pp. 221-27.

9. I. Barin, M. Modigell, and F. Sauert: Metall. Trans. B, 1987, vol. 18 B, pp. $347-54$.

10. A.W. Weimer, J.K. Dahl, A.A. Lewandowski, C. Bingham, K.J.R. Buechler, and W. Grothe: Solar-Thermal Fluid-Wall Reaction Processing, U.S. Patent 7,033,570 B2, Apr. 2006.

11. F.D. Ricou and D.B. Spalding: J. Fluid Mech., 1961, vol. 11, pp. 21-32.

12. A.F. LaCamera: Carbothermic Aluminum Production Using Scrap Aluminum as a Coolant, U.S. Patent 6,465,260 B2, Nov. 2002

13. Y. Kimura, T. Sato, and C. Kaito: Carbon, 2004, vol. 42, pp. 33-38.

14. J. Steinbeck, G. Braunstein, M.S. Dresselhaus, T. Venkatesan, and D.C. Jacobson: J. Appl. Phys., 1985, vol. 58 (11), pp. 4374-82.

15. E.T. Turkdogan: Physical Chemistry of High Temperature Technology, Academic Press, New York, NY, 1980, pp. 121-22.
16. F.J. Cherne, III and P.A. Deymier: Scripta Mater., 2001, vol. 42, pp. 985-91.

17. H.M. Lu, G. Li, Y.F. Zhu, and Q. Jiang: J. Non-Cryst. Solids, 2006, vol. 352, pp. 2797-2800.

18. V. Sarou-Kanian, F. Millot, and J.C. Rifflet: Int. J. Thermophys., 2003, vol. 24 (1), pp. 277-86.

19. M. Kobashi, T. Choh, and Y. Yasutaka: Nippon Kinsoku Gakkaishi/J. Jpn. Inst. Met., 1990, vol. 54 (8), pp. 933-40.

20. D. Goberman, Y.H. Sohn, L. Shaw, E. Jordan, and M. Gell: Acta Mater., 2002, vol. 50, pp. 1141-51.

21. Z. Chang-sheng Zhai, J. Wang, F. Li, R. Wu, J.-c. Tao, and B.-d. Sun: Mater. Sci. Eng., A, 2005, vol. 392 (1-2), pp. 1-7.

22. T. Sukawa and M. Iguchi: ISIJ Int., 2005, vol. 45 (8), pp. 1145-50.

23. G.E.H. Joosten, J.G.M. Schilder, and A.M. Broere: Trans. I. Chem. E., 1977, vol. 55, pp. 220-23.

24. A. Bakker and J.J. Frijlink: Chem. Eng. Res. Des., 1989, vol. 67, pp. $208-10$.

25. C. Malmstrom, R. Keen, and L. Green, Jr.: J. Appl. Phys., 1951, vol. 22 (5), pp. 593-600.

26. P. Wagner, A.R. Driesner, and L.A. Haskin: J. Appl. Phys., 1959, vol. 30 (2), pp. 152-54

27. J.M. Molina, A. Rodríguez-Guerrero, M. Bahraini, L. Weber, J. Narciso, F. Rodríguez-Reinoso, E. Louis, and A. Mortensen: Scripta Mater., 2007, vol. 56, pp. 991-94.

28. L.C. Pardini, F.L. Neto, and J.L. de Almeida Fereira: Mater. Res., 2006, vol. 9 (2), pp. 193-97.

29. T.K. Sherwood, R.L. Pigford, and C.R. Wilke: Mass Transfer, International Student ed., McGraw-Hill Ltd., Kogakusha, Japan, 1975, pp. 241-47.

30. D. Kunii and O. Levenspiel: Fluidization Engineering, John Wiley \& Sons, Inc., New York, NY, 1969, pp. 382-84.

31. A. Atkinson, S. Barnett, R.J. Gorte, J.T.S. Irvine, A.J. Mcevoy, M. Mogensen, S.C. Signhal, and J. Vohs: Nat. Mater., 2004, vol. 3 (1), pp. 17-27.

32. M.R. Haines, W.K. Heidug, K.J. Li, and J.B. Moore: J. Power Sources, 2002, vol. 106, pp. 377-80.

33. R.L. Bannister, R.A. Newby, and W.C. Yang: Trans. ASME, J. Eng. Gas Turbines Power, 1999, vol. 121, pp. 38-45.

34. M.J. Bruno: Final Technical Progress Report for 2000 July-2004 December on Aluminum Carbothermic Technology, Cooperative Agreement No. DE-FC36-00ID13900, submitted to the United States Department of Energy, Golden, CO, Dec. 2004.

35. H.H. Kellogg: J. Met., 1974, vol. 26, pp. 25-29. 